\title{
USING DEM TO INVESTIGATE BOUNDARY CONDITIONS FOR ROCKING URM FAÇADES SUBJECTED TO EARTHQUAKE MOTION
}

\section{FRANCISCO GALVEZ ${ }^{1 *}$, LUIGI SORRENTINO ${ }^{2}$, DMYTRO DIZHUR ${ }^{3}$ AND JASON M. INGHAM ${ }^{4}$}

7
${ }^{1} \mathrm{PhD}$ candidate. University of Auckland, Civil and Environmental Engineering Department, Newmarket Campus, 314-390 Khyber Pass Road, Auckland 1023, Aotearoa New Zealand email: fglv390@aucklanduni.ac.nz, (*corresponding author)

${ }^{2}$ Associate Professor. Sapienza Università di Roma, Department of Structural and Geotechnical Engineering, Faculty of Architecture, via Antonio Gramsci 53, 00197 Roma, Italy email: luigi.sorrentino@uniroma1.it

\footnotetext{
${ }^{3}$ Associate Professor. University of Auckland, Civil and Environmental Engineering Department, Newmarket Campus, 314-390 Khyber Pass Road, Auckland 1023, Aotearoa New Zealand email: ddiz001@aucklanduni.ac.nz
} email: j.ingham@auckland.ac.nz 
39 Abstract: Façade overturning is a frequently observed collapse mechanism occurring in unreinforced masonry (URM) buildings during high-intensity earthquake-induced shaking. Following complete separation from a building, the rocking motion of a URM façade and the associated impact against the return walls are the factors that continue to contribute to the façade out-of-plane capacity. Seismic vulnerability studies of URM façades have historically neglected the interaction between building earthquake response and the rocking response of the façade, whereas in the study reported herein this interaction was analysed using the discrete element modelling (DEM) approach, resulting in a façade out-of-plane capacity reduction. The increment in the dynamic rocking capacity caused by the frictional connection between the URM façade and the building was also analysed and is reported.

\section{INTRODUCTION}

Façade overturning is a collapse mechanism that is routinely observed after high-intensity earthquakes (Lagomarsino, 1998, Benito et al., 2007, Hess, 2007, Dizhur et al., 2010), being a critical life-safety hazard because out-of-plane failure can jeopardise the gravity-load bearing capacity of the building (Bruneau, 1994) and can result in large quantities of masonry debris falling outside the building footprint (Abeling and Ingham, 2020). Therefore, details of the collapse behaviour of unreinforced masonry (URM) façades need to be well understood.

59 Façades that lose their connection with the adjoining return walls have been observed to behave as rocking rigid-bodies when disintegration of the masonry did not occur (Shawa et al., 2012, Lagomarsino, 2015, Giresini et al., 2018). Amongst the different approaches adopted to 
simulate the free rocking behaviour of rigid bodies, the strategy originally developed by Housner (1963) is the most widely used where the rocking equations of motion represent a rigid block rocking on a simply supported rigid base, with the assumption that the coefficient of friction is large enough to avoid sliding. The cyclic rocking motion of a block dissipates energy when impacting the ground, which was modelled by Housner (1963) using the coefficient of restitution, such that a reduction of angular velocity occurs by assuming the conservation of angular momentum before and after every impact. Several authors have revisited the Housner (1963) formulation to include sliding and bouncing in the rocking motion (Aslam et al., 1975, Ishiyama, 1982, Psycharis and Jennings, 1983), to account for different material stiffnesses and different friction characteristics at the block-base contact (ElGawady et al., 2011, Lipo and de Felice, 2016, Ther and Kollár, 2016), to reduce discrepancies with experimental observations (Lipscombe and Pellegrino, 1993, Kalliontzis et al., 2016), or to reduce the complexity of the rocking motion formulation in order to facilitate the development of a closed-form solution to the problem (Casapulla and Maione, 2017).

The abovementioned research gives a solution to the problem of a free-standing rocking block, but many rocking elements that concern the earthquake engineering community are one-sided rocking blocks (e.g. hospital or laboratory equipment generally placed next to walls, or rocking unreinforced masonry such as URM façades). The motion of the façades when constrained by impacting with the return walls makes the problem significantly more complex, and therefore

81 less research has been conducted on this topic. Impact interaction has been accounted for by restricting the cyclic motion and including an extra coefficient of restitution that changes the amplitude and the sign of the rotational velocity instantaneously to account for the change in motion direction and the energy dissipated at the contact (Sorrentino et al., 2008, Bao and Konstantinidis, 2020). Another adopted approach was to assume that the energy dissipated between the rocking blocks and the adjacent walls was negligible (Sigurdsson et al., 2019). 
One-sided rocking models that account for interaction between the rocking façade and steel tie rods were also reported (Giresini et al., 2015, Giresini and Sassu, 2016, Giresini, 2017, AlShawa et al., 2019) and simplified approaches were proposed where the interaction between façades and return walls was represented by a bed of springs (Giresini and Sassu, 2016, Giresini, 2017). Using the same modelling strategy, more recent models have included twodirectional motion of more complex masonry shapes (e.g. corner failure macroblock) (Casapulla et al., 2019a, Giresini et al., 2019). Researchers agree that the overturning frequency of façades is reduced when the damping associated with impact with the return wall is increased (Sorrentino et al., 2008, Sorrentino et al., 2011, Bao and Konstantinidis, 2020), and when steel ties are used as a strengthening solution (Giresini, 2017, AlShawa et al., 2019). Bao and Konstantinidis (2020) considered a sliding-rocking block adjacent to a wall and concluded that decreasing the friction coefficient and reducing the gap between block and wall are beneficial strategies to increase the dynamic stability against overturning while accepting sliding. Casapulla et al. (2017) provides a detailed review of the latest advances on rocking and kinematic analysis of URM walls subjected to earthquakes.

102 Façades that span over several stories and where the parapet is located at the top of the URM 103 building experience distinctly different earthquake motion than that occurring at ground level, because earthquake motion at the ground surface is modified and amplified as it travels through the structural elements of the building. This amplification phenomenon is acknowledged and well documented in the literature (Priestley, 1985, Derakhshan et al., 2014, Degli Abbati et al.,

107 2018) when assessing the seismic performance of URM parapets or upper level URM walls.

108 The inelastic behaviour of the building also modifies the ground motion up the building height, 109 dissipating energy as building damage occurs. Depending on the ductility and the stiffness of 110 the building, the modification of the ground motion may be either beneficial or detrimental to 111 the seismic demand of the upper level walls (Menon and Magenes, 2011). However in the case 
of URM façades, studies generally do not account for different input motions at the base and

113 up the height of the return walls (Sorrentino et al., 2008, Shawa et al., 2012, Giresini et al.,

1142019 , Sigurdsson et al., 2019). In the study presented herein four topics are addressed using

115 the discrete element method (DEM): (1) finding a simple alternative to model the amplification

116 of ground motion occurring in URM buildings, (2) developing and experimentally validating a

117 suitable strategy to assign a damping parameter for one-sided rocking façades, (3) studying the

118 seismic vulnerability of URM façades with different boundary conditions, and (4) analysing

119 the influence when including the seismic behaviour of the building during an assessment of the

120 vulnerability of rocking façades. Ideally, either the complete building or alternatively part of

121 the building would be micro-modelled and analysed with thousands of degrees of freedom

122 (DOF), but such an approach is computationally demanding making such an undertaking impractical. Instead, an alternative method was investigated and the seismic response for various configurations of lumped mass-spring models were compared. Once the simpler model configuration was selected, the resulting motion at multiple levels within the building was extracted and used as input to the simulated return walls of an experimentally validated 3D DEM simulation of rocking façades spanning over two building storeys.

\section{COMPARISON BETWEEN LUMPED MASS-SPRING AND 3D DEM MODELS}

129 A single-unit two-storey URM case study building that was used in the Italian ReLUIS III research Project Masonry Structures was selected in order to study the modification of ground motion occurring up the height of a URM building. The selected building was designed with a

132 relatively simple geometry that was intended to reveal interaction effects between piers and

133 spandrels. The geometry of the case study building also facilitated a study of the effects of stress redistribution in the presence of walls with different stiffness, plus a study of torsional 

modelling techniques (Cattari et al., 2018, Olcese, 2018). As part of the study reported herein, the geometry of the building was modelled using the software Rhinoceros ${ }^{\circledR}(\mathrm{McNeel}$ and Associates, 2014), which allows a script to be run that contains an algorithm capable of exporting a text file of the building geometry compatible with the DEM software 3DEC (Itasca,

140 2013) (see Figure 1).
(a) Rhinoceros ${ }^{\circledR}$ (Dimensions in $\left.\mathrm{m}\right)$
(b) DEM

143 The DEM software allows modelling of every masonry unit by independent rigid or deformable

144 elements connected to each other by nonlinear interfaces. The case study building presented 145 herein was modelled with rigid elements referred to herein as bricks, and linearly elastic 146 interfaces. This linear behaviour complies with the assumption that façades and parapets will 147 collapse before the building has suffered enough damage to alter its fundamental frequency, 148 that will allow a simplification of the problem to focus on the façade boundary condition 149 problem addressed herein. Rigid diaphragms with elastic connections were modelled as per 150 Gubana and Melotto (2019). The diaphragm comprised evenly spaced rigid beams oriented 151 parallel to the shorter walls and placed on top of the masonry walls, whose thickness was 152 reduced to host the beam support. Elastic contacts between the beam ends and the masonry were generated and in order to simulate actual diaphragms, a rigid panel was modelled on top

154 of the beams and connected to them with elastic contacts. This simplified modelling strategy 155 allowed the cyclic behaviour of a timber floor to be considered in the DEM model.

156 The interfaces between the bricks were defined by three shear and normal material parameters: 157 normal stiffness $\left(j_{k n}\right)$; shear stiffness $\left(j_{k s}\right)$; friction angle $\left({ }^{\circ}\right)$. Generally, the estimation of $j_{k n}$ is 
calculated as $E / s$, where $E$ is the Young modulus and $s$ is the joint spacing (see Galvez et al.

159 (2018) for further details). The value of $E$ for the case study building was 1,800 MPa, and the

160 dimensions of the bricks were $24 \mathrm{~L} \times 6 \mathrm{H} \times 12 \mathrm{~W} \mathrm{~cm} \mathrm{~cm}^{3}$. However, application of these parameters

161 to forecast $j_{k n}$ led to an overestimation of the overall stiffness of the building and a much lower

162 fundamental period than is typical for a 2-storey URM building. Hence it was decided to reduce

$163 j_{k n}$ until the building modes of vibrations resulted in values that were similar to previous

164 observations but respected the relationship with brick dimensions. This tuning strategy to

165 establish the material properties has been implemented by multiple researchers

166 (Papantonopoulos et al., 2002, Psycharis et al., 2003, Lemos and Campos Costa, 2017, Meriggi

167 et al., 2019) who calibrated their models by best fitting stiffness parameters to match experimental dynamic behaviour or by replicating previous similar research. There are three types of contact surfaces around a brick, each with its own properties influenced by the brick dimensions: head joint $\left(j_{k n}=1,280 \mathrm{MPa} / \mathrm{m}, j_{k s}=422 \mathrm{MPa} / \mathrm{m}\right.$, friction angle $\left.=30^{\circ}\right)$, bed joint $\left(j_{k n}=5,120 \mathrm{MPa} / \mathrm{m}, j_{k s}=1,690 \mathrm{MPa} / \mathrm{m}\right.$, friction angle $\left.=30^{\circ}\right)$ and collar joint $\left(j_{k n}=2,560\right.$ $\mathrm{MPa} / \mathrm{m}, j_{k s}=845 \mathrm{MPa} / \mathrm{m}$, friction angle $\left.=30^{\circ}\right)$. The aforementioned joint material properties were selected to ensure that the eigenvalue analysis delivered a period of $0.25 \mathrm{~s}$ for the $Y$ translational mode of vibration, coinciding with the estimate given by equation $\mathrm{T}=0.0625 \cdot h^{0.75}$ from NZS1170.5 (2004) and AS1170.4 (2007). The same analysis delivered a period of $0.16 \mathrm{~s}$ for the $Z$ rotational mode (see Figure 2). To these frequencies 5\% and 3\% Rayleigh mass

177 proportional (MP) damping ratios were applied, respectively. Rayleigh damping can be derived

178 using MP or stiffness proportional (SP) damping, with the latter having a strong influence on 179 the timestep size of the simulation. A time-history simulation of the complete building using DEM (CBDEM) was considered highly computationally demanding even when using MP

181 damping. Consequently a simplified structure (SBDEM) without the front and rear façades in 

eigenvalue analysis (see Figure 2).
(a) $1^{\text {st }}$ mode of
(b) $1^{\text {st }}$ mode of
(c) $2^{\text {nd }}$ mode of
(d) $2^{\text {nd }}$ mode of
CBDEM $(\mathrm{T}=0.25 \mathrm{~s})$
$\operatorname{SBDEM}(\mathrm{T}=0.27 \mathrm{~s})$
CBDEM $(\mathrm{T}=0.16 \mathrm{~s})$
SBDEM $(\mathrm{T}=0.17 \mathrm{~s})$

187 Considering the directionality of the input motion, only the modes of vibration with significant

Figure 2: First and second modal shapes and periods in the $Y$ direction of the complete and the simplified structure calculated using DEM modal analysis

effective modal mass in the $Y$ axis were considered, with a difference of 0.01-0.02 s between the modal frequencies and similar deformed shapes being observed in Figure 2. Subjecting even the SBDEM building to multiple time-history analyses would require a great computational effort and would highly restrict the number of earthquakes that could be amplified as input to the rocking façade simulations. Hence, developing a simpler easy-to-run equivalent model had a high potential for future studies. The simpler model chosen to compute the dynamic behaviour of the building was based on the solution of the explicit formulation of the equation of motion of a spring-mass model with translational degrees of freedom and varying number of springs and lumped masses (SMDOF) performed in the software Matlab® (MathWorks, 2008). All the masses of the model were divided equally per lumped mass, and the summation of all mass was equal to the mass of the SBDEM model. Similarly, all the stiffnesses were equal and adjusted so that the first mode of vibration matched the value of $0.27 \mathrm{~s}$ that was obtained from the SBDEM model (Figure $2 \mathrm{~b}$ ), while damping was fixed at $5 \%$. After confirming the directional dynamic equivalence between the CBDEM and the SBDEM (see Figure 2), the seismic response of the SBDEM when subjected to two of the ground motions in Table 1 (BUCAR0 and RRS228) was compared to the response of the SMDOF. 
(a) Time-history response

(b) Response Spectra

(c) Power Spectra

208 The SMDOF model that provided results most similar to the results from the SBDEM was

209 identified by comparing the weighted mean error (WME) between models using SBDEM as

210 the reference. The WME was obtained from the time-history responses and the acceleration

211 and power spectra (see Figure 3) with the following formulation:

$$
\mathrm{WME}=\frac{\int_{0}^{X}\left|Y_{D E M}(x)-Y_{D O F}(x)\right| d x}{\int_{0}^{X}\left|Y_{D E M}(x)\right| d x}
$$

where $x$ was time, period or frequency, $Y$ was acceleration, spectral acceleration or power amplitude depending on the evaluated case and $X$ was the total range of $x$ considered. Observing Table 2, the errors generated for a 4DOF and 5DOF models were found to have minimal

217 difference. Consequently a 4DOF substitute structure was chosen to obtain the motion to apply 218 to the rocking parapets and façade. A 4DOF model is more efficient than a 2DOF with masses

219 lumped at floors, because most of the mass of typical masonry buildings is located in the walls

220 rather than in the diaphragms. It was assumed that the primary building structure did not suffer damage during the earthquake and that even if damage appeared, the parapet and façade would collapse before the building sustained sufficient damage to change the stiffness and therefore the response. DEM simulations are known to have high-frequency numerical noise in the solution, known as the "rattling effect" (Lorig and Hart, 1993, Papantonopoulos et al., 2002, Jing and Stephansson, 2007, Dimitri et al., 2011). Because of the high-frequency nature of this 
effect, MP damping is unable to attenuate this effect, which can affect the simulation depending on the magnitude of the frequencies of phenomena to be modelled. The rattling effect for the SBDEM can be observed from 0 to $1 \mathrm{~s}$ of the response in Figure $3 \mathrm{a}$ and in the peak around $0.08 \mathrm{~s}$ of the spectra in Figure 3c. In this problem, the rattling error did not affect the main response of the building, which was approximately $0.27 \mathrm{~s}$.

\section{VALIDATION OF DAMPING PARAMETERS FOR ROCKING FAÇADES}

234 Rayleigh damping makes use of the constants $\alpha$ (MP) and $\beta$ (SP) to construct the damping matrix when performing dynamic analysis. The relationship for the damping ratio $\left(\zeta_{n}\right)$ for any circular frequency $\left(\omega_{n}\right)$ that results from the application of $\alpha$ and $\beta$ can be found in Bathe and Wilson (1976) as:

$$
\zeta_{n}=\frac{\alpha}{2 \cdot \omega_{n}}+\frac{\beta \cdot \omega_{n}}{2}
$$

Rocking simulations using SP damping have been recommended by several authors (DeJong, 2009, Tomassetti et al., 2019) because MP damping may introduce overdamped low frequencies and result in unrealistic results. However, a systematic approach has not yet been developed to assign the value of SP damping for a 1SR wall. Conversely, a formulation experimentally developed by Sorrentino et al. (2011) allowed for an estimation of the restitution coefficient $\left(e_{1 \mathrm{SR}}\right)$ caused by multiple impacts of the block into the return walls as: 


$$
e_{1 \mathrm{SR}}=\left(1-\frac{3}{2} \cdot \sin ^{2} \alpha\right)^{2} \cdot\left(1-\frac{3}{2} \cdot \cos ^{2} \alpha\right)
$$

248 A parametric analysis was performed using single DEM blocks to represent the cracked rocking façade and interaction with the return walls to investigate $\beta$ for $1 \mathrm{SR}\left(\beta_{1 \mathrm{SR}}\right)$ walls based on their equivalent $e_{1 \mathrm{SR}}$. The $j_{k n}$ at the bottom of the walls was calculated as $E / h$, where $h$ is the height, and $j_{k n}$ for the joint interacting with the return walls was calculated as $E / L$, where

$252 L$ is the average length of the triangular-shaped URM block assumed to develop in the return wall once cracking occurs at $45^{\circ}$, according to the observations of Giresini and Sassu (2016). Assigning the value of $j_{k n}$ for the return wall is a challenging task with various limitations as outlined by Giresini (2017). First, it is common practice to assume that the stiffness of the return walls is constant, even though it is known that the seismic response of URM buildings is characterised by progressive damage, and the corresponding change in stiffness can have an influence on the out-of-plane response of URM walls (Menon and Magenes, 2011). Secondly, the cracks on the return walls are assumed to occur at $45^{\circ}$ even though the crack angle is actually unknown.

261 Four batches of simulations having varying block geometry [height $(h)$ and thickness $(b)$ ] and

262 varying stiffness of the interface between the returning walls and the façade were performed and the results are summarised in Figure 4. The façade was displaced from the return walls, released, and allowed to rock and impact against the return walls. A range of $\beta_{1 \text { SR }}$ parameters was applied to the walls where the first three bounces after impacting with the return walls were studied based on the observations of Sorrentino et al. (2011), who found that the experimental coefficient of restitution of the third impact calculated using the Housner (1963) 
can be seen in equation 4 , where $\left|\theta_{n}\right|$ is the maximum absolute rotation at the $n^{\text {th }}$ impact and

$\eta=\tan ^{-1}(b / h)$

$$
e_{\text {exp }}=\sqrt[2 n]{\frac{1-\left(1-\frac{\left|\theta_{n}\right|}{\eta}\right)^{2}}{1-\left(1-\frac{\left|\theta_{0}\right|}{\eta}\right)^{2}}}
$$

271

272

273

274

275

276

277

278

279

280

281

282

283

284

285

286

wherein $b$ has units of $\mathrm{m}$, and $E$ of $\mathrm{MPa}$.

Figure $4 \mathrm{a}$ shows the values of $\beta_{1 \mathrm{SR}}$ used as part of the parametric study for various values of $h$ and a constant value of $b=0.11 \mathrm{~m}$. The values to parametrise $\beta_{1 \mathrm{SR}}$ were chosen ranging from a maximum expected for a single rocking block as derived from DeJong (2009) and a minimum obtained for two blocks vertically stacked obtained using the same principles as DeJong (2009) recommended. Assuming from Sorrentino et al. (2011) that $e_{\text {exp }}$ is between $64 \%$ and $72 \%$ of $e_{1 \text { SR }}$ on the first impact, between $74 \%$ and $86 \%$ on the second impact, and that on the third impact eexp is similar to $e_{1 \mathrm{SR}}$, the best fitting free rocking results of DEM simulations using $\beta_{1 \mathrm{SR}}$ are highlighted in Figure 4a. To calculate the best fitting results, $e_{\exp }$ (Equation 4) was computed from the results of the DEM simulations and compared to the aforementioned percentages of $e_{1 \mathrm{SR}}($ Equation 3 ) on the first, second and third bounce. The best fitting trends for different $h / b$ of façades with $b=0.11,0.3 \mathrm{~m}$ and $E=1800,4050 \mathrm{MPa}$, as observed in Figure $4 \mathrm{~b}$, where studied to obtain a dimensional regression for estimating $\beta_{1 \mathrm{SR}}$ as follows:

$$
\beta_{1 \mathrm{SR}}=\left(\frac{b}{384}-\frac{E}{5.6 \times 10^{6}}+0.00074\right) \cdot e^{\left(h / b \cdot \frac{-E+6572}{1.2 \times 10^{5}}\right)}
$$

(a) Values of $\beta_{1 \mathrm{SR}}$ for walls with $b=0.11 \mathrm{~m}, E=$ $1800 \mathrm{MPa}$ and different values of $h / b$. (b) Best fitting $\beta_{1 \mathrm{SR}}$ for different values of $E$ and geometry variations

Figure 4: Parametric studies. 
The experimental setup reported by Sorrentino et al. (2011) and by Shawa et al. (2012) were used to validate the predictions made using equation 5. Sorrentino et al. (2011) tested a wall of $0.8 \mathrm{~m}$ height, $0.11 \mathrm{~m}$ thickness, $E=1800 \mathrm{MPa}$ and density $=1750 \mathrm{~kg} / \mathrm{m}^{3}$ built with solid clay bricks together with two return walls disconnected with a dry joint (see Figure 5a). The tested wall was displaced from the return walls, released and allowed to rock in order to study the attenuation caused by the impacts against the return walls. Observing the time-history plots in Figure $5 \mathrm{~b}, \mathrm{c}$, the simulation performed using $\beta_{1 \mathrm{SR}}=0.00025$ was found to be closest to the experiments during the first bounce, but from the values of $e_{\exp }$ plotted in Figure $5 \mathrm{~d}$ the simulation with $\beta_{1 \mathrm{SR}}=0.001$ showed similar damped motion as the experiments during the second and third bounces. The value of $\beta_{1 \text { SR }}$ obtained using equation 5 was 0.00095 , which was

300 deemed an acceptable result for being only 5\% different from $\beta_{1 \mathrm{SR}}=0.001$. After the first bounce of simulations with $\beta_{1 \mathrm{SR}}=0.000125,0.00025,0.0005$ and 0.001 the majority of the energy was dissipated and the second and third bounces remained mostly undamped. Alternatively, simulations with $\beta_{1 \mathrm{SR}}=0.002,0.004$ and 0.0058 were found to be overdamped after the first impact.

(a) Experimental setup (Sorrentino et al., 2011)

(c) Expanded view between $0.9 \mathrm{~s}$ and $1.9 \mathrm{~s}$ (b) Complete time-history

(d) Values of $e_{\exp }$ for different simulations using $\beta_{1 \mathrm{SR}}$ compared to $e_{1 \mathrm{SR}}$ and experimental testing

Figure 5: Experimental testing from Sorrentino et al. (2011) and simulations using 3DEC

Shawa et al. (2012) subjected a $3 \mathrm{~m}$ high and $0.25 \mathrm{~m}$ thick tuff masonry wall to four earthquakes named BagnirWE, SturWE, R1168EW and CalitWE (more information can be found in Shawa

309 et al. (2012)). The wall was constructed with return walls to perform 1SR and a physical gap 310 of $4 \mathrm{~mm}$ was reported between the return walls and the overturning wall. During repeated 311 rocking testing debris accumulated under the wall and prevented the wall from returning to its 
312 initial vertical position, such that on repeated shaking the wall had rotated $(\varphi)$ initial geometry.

313 The shake table experimental campaign performed by Shawa et al. (2012) was simulated using

314 SP damping and the reported material properties of $E=4050 \mathrm{MPa}\left(j_{k n}=1350 \mathrm{MPa} / \mathrm{m}\right)$ and

315 density $=1810 \mathrm{~kg} / \mathrm{m}^{3}$, with care taken to account for the reported geometrical irregularities due

316 to debris lodged beneath the wall (Figure 6a,b). It is worth noting that Shawa et al. (2012) was

317 capable of reproducing the 1SR tests with a model based on Housner (1963) approach taking

318 into account the multiple impacts energy dissipation for the coefficient of restitution and with

319 a 2D DEM model with SP damping. Applying equation 5, $\beta_{1 \mathrm{SR}}$ was found to be 0.00086 , a very

320 similar value as the one found by trial and error by Shawa et al. (2012) $\left(\beta_{1 \mathrm{SR}}=0.00094\right)$ for a

321 test of the early stages of the testing sequence. In later stages the value of damping increased

322 as a consequence of damage due to mortar deterioration and cracking due to the impact with

323 the return walls (Shawa et al., 2012). Using equation 5 as a starting point for the assignation of

$324 \beta_{1 \text { SR }}$, the damping value was slowly increased until reaching a good agreement between

325 experimental observations and 3D DEM as seen in Figure 6. When simulating the four

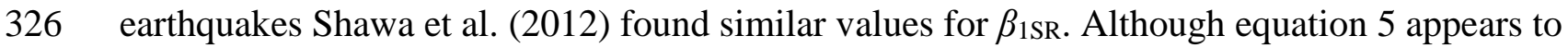

327 deliver reasonable estimation of $\beta_{1 \mathrm{SR}}$, additional research is required to achieve a robust 328 criterion for selection of a damping value that accounts for diffenre boundary conditions 329 including free-standing blocks.
(a) DEM model
(b) Diagram of tilted rocking facade
(c) BagnirWE, $\varphi=0.191^{\circ}$
(d) SturWE, $\varphi=0.210^{\circ}$
(e) R1168EW, $\varphi=0.272^{\circ}$
(f) CalitWE, $\varphi=0.348^{\circ}$ 


\section{DIFFERENT BOUNDARY CONDITIONS FOR ROCKING FAÇADES}

333 The rocking interaction between the façade (dimensions in Figure 1a) and the case study URM

334 building was simulated using three structural configurations and two variations in material

335 characteristics to arrive at five different boundary condition scenarios that utilised springs (see

336 Figure 7) calibrated to replicate the deformation of the return wall. First, each return wall was

337 modelled using a single cohesionless block behind the façade and subjected to the same ground

338 motion as at the façade base (W1, see Figure 7a). Secondly, each return wall was modelled

339 using four cohesionless blocks positioned at the back of the façade, with the ground motion

340 applied to the base and with the amplified motions extracted from each lumped mass of the

341 4DOF model being input to each block positioned above the base (W2, see Figure 7b).

342 Considering the minimal differences between 4DOF and 5DOF models (Table 2), the use of

343 the former model was considered adequate. The aforementioned models were also simulated

344 with $0.1 \mathrm{MPa}$ cohesion and 0.07 MPa tensile strength (Giaretton et al., 2016) on the contact

345 interface between the façade and the return walls. Finally, a more detailed model that accounted

346 for friction (friction angle $=30^{\circ}$ ) with no cohesion between the façade and the return walls,

347 and including the 4DOF amplified motions, was modelled (W3, see Figure 7c). All façade

348 configurations were modelled using a value of $\beta_{1 \mathrm{SR}}=0.00276$ according to equation 5 .
(a) W1
(b) W2
(c) W3 scheme (Colours represent displacement magnitude without scale).

Elements representing connection between the façade and the return walls in W3 were carefully modelled to avoid increments in the overturning resistance being in excess of a realistic contribution of masonry interlocking. There were two crucial phenomena to keep in mind while assigning the degrees of freedom to the return wall bricks: (1) friction forces resulting on the 
brick interfaces are proportional to the weight from the upper bricks while the façade is rotating with respect to the return wall, (2) the interlocked bricks of the return walls need to rotate in opposite directions to form the crack between the façade and return walls (see Figure 8b). Therefore, during the induced motion each brick in the return wall (Figure 8a) had free translational movement in the $Z$ (vertical) direction and free rotation around the $X$ axis, while having the remaining degrees of freedom restricted and being capable of moving horizontally with the amplified input motion. Low values of the normal and shear stiffnesses of the connection between the façade and the return walls were chosen in order to reduce computational time $\left(j_{k n}=1,100 \mathrm{MPa} / \mathrm{m}\right.$ and $\left.j_{k s}=440 \mathrm{MPa} / \mathrm{m}\right)$. These values did not influence the final capacity of the wall but only the stiffness of the connection (Mordanova et al., 2017,

366 Pulatsu et al., 2020), which was suitable for this study. Due to the rigidity of the façade and 367 return wall elements, the lower wall courses remained connected by their edges when the rotation was well advanced, resulting in a non-realistic resistance. For this reason, lower elements of the return walls were modelled with an inclined interface to allow breaking in shear (see lower courses of Figure 8a). The partial elements from the façade (see Figure 8a) were connected using an interface with appropriate material properties for fired clay bricks to allow for deformation and detachment if needed. In order to reduce the computation time, the least possible number of elements were included by modelling only one column of return wall bricks, and by increasing and modifying the dimensions of the bricks compared to what are usually used in construction $\left(0.25 \mathrm{~L} \times 0.324 \mathrm{H} \times 0.375 \mathrm{~W} \mathrm{~m}^{3}\right)$. Prior to running the dynamic

376 simulation a pushover test was performed to confirm that the boundary conditions were realistically modelled. Figure 8c shows good agreement between kinematic capacity curves developed by Casapulla et al. (2019b) and the DEM simulation.

(a) Elements in $\mathrm{W} 3$

(b) Scheme of generic façade and return wall separation (c) Comparison between kinematic and DEM capacity curve 
381 The five different models shown in Figure 7 were subjected to the four earthquakes presented

382 in Table 1 in the positive (+) and negative (-) directions, with increasing acceleration. The

383 dynamic capacity curve of each wall configuration in terms of PGA and maximum top

384 displacement $(d)$ of the façade was normalized by the wall width $(w)$ and is plotted in Figure

3859 , showing that W2 tended to be equally vulnerable or more vulnerable than W1. Though by a

386 very small margin, for BUCAR0-, BUCAR0+, 1ST280-, HVSC1+ and RRS228+ the dynamic

387 behaviour of the building caused a slightly more vulnerable capacity for W2. Conversely, the

388 dynamic amplification of the building caused a marked reduction in façade capacity for the

389 remainder of the cases. When cohesion was added to the $\mathrm{W} 1$ model a clear increment in

390 resisting acceleration was observed, while when cohesion was included in the W2 wall the

391 motion of the return walls made the rigid façade detach at an early stage, resulting in premature

392 collapse. The dynamic incremental capacity curve of W3 highlights the importance of

393 interlocking on out-of-plane response. BUCAR0 and RRS228 records both feature a large pulse

394 and resulted in IDA curves that matched well with the pushover curve obtained via quasi static

395 analysis undertaken by Casapulla et al. (2019b). The results from 1ST280 and HVSC1 showed

396 that the capacity of rocking blocks when subjected to earthquakes can be much higher than

397 obtained from equivalent-static pushover. 
RRS228

$1 \mathrm{ST} 280$

\section{HVSC1}

399

400

401

402

\section{CONCLUSIONS}

403 Nonlinear incremental dynamic analyses were performed using the three dimensional discrete

404 element method to investigate the vulnerability of a rocking façade as part of a two-storey case

405 study unreinforced masonry building. Due to computational restrictions and simulation time

406 practicality, dynamically equivalent strategies were developed to simulate the building

407 behaviour associated with amplification of the ground motion and interaction between the

408 rocking façade and the return walls. The adopted strategy consisted of developing a 4 degrees

409 of freedom spring-mass model of the two-storey unreinforced masonry building that was used

410 to efficiently simulate several time-history analyses and obtain the amplified motion. The

411 amplified motion of each lumped mass was applied to a discrete element method model of the

412 rocking façade with different boundary conditions. The equivalence between a full-scale 3D

413 discrete element method discretised model and the 4 degrees of freedom substitute structure

414 was demonstrated by subjecting both models to earthquake ground motions and comparing the

415 time history performance of the building motion, the spectral acceleration and the frequency

416 power spectra. 
417 In order to assure that the rocking simulations of facades using discrete element method were

418 performed accurately, a formulation was developed to assign an appropriate value of damping

419 following a stiffness proportional damping approach. The capability of the developed

420 formulation to be used for any façade independent of the geometry and material properties was

421 validated using experimental free rocking and earthquake shake-table testing.

422 Comparisons of the incremental dynamic capacity curves showed that modelling the behaviour 423 of the building, as opposed to the usual strategy of having non-amplified excitation of the return 424 walls, can reduce the capacity of the façade by as much as $60 \%$ depending on the characteristics 425 of the earthquake. This observation implies that when nonlinear time-history analyses are used 426 to assess the overturning vulnerability of one-sided rocking parts, the capacity of such elements 427 may be overestimated. Furthermore, applying amplified motion to return walls having cohesive 428 bond resulted in premature collapse of the façade such that this strategy is not advised to be used in future studies. On the contrary, detailed modelling of the interlocking elements of the façade with the return walls that were subjected to amplified motion was found to considerably 431 increase the capacity of the façades, depicting greater capacity than shown via the pushover analysis. While the capacity value will change depending on the level of connectivity between the return walls and the façade, the increment in capacity due to rocking behaviour will remain.

434 Lower bricks of the return walls in the detailed model were designed specifically for the problem studied herein. Further research of the rocking problem is required to address stress concentration occurring in lower rigid elements due to the overturning moment, because this concentration could lead to an overestimation of the rocking capacity.

439 Data Availability Statement. Some or all data, models, or code that support the findings of 440 this study are available from the corresponding author upon reasonable request. 
442 Acknowledgements. This project was (partially) supported by QuakeCoRE, a New Zealand

443 Tertiary Education Commission-funded Centre. This is QuakeCoRE publication number 634.

444 The authors also gratefully acknowledge the software 3DEC provided by Itasca consulting 445 group under the Itasca Educational Partnership program. Use was made in this paper of a solid 446 geometry generation tool developed by Dr. Daniele Malomo, (MDRG-Matthew DeJong 447 Research Group, University of California, Berkeley), who is gratefully acknowledged.

\section{REFERENCES}

450 Abeling, S. and J. M. Ingham (2020). "Volume loss fatality model for as-built and retrofitted 451 clay brick unreinforced masonry buildings damaged in the 2010/11 Canterbury earthquakes." 452 Structures 24: 940-954.

453 AlShawa, O., D. Liberatore and L. Sorrentino (2019). "Dynamic One-Sided Out-Of-Plane 454 Behavior of Unreinforced-Masonry Wall Restrained by Elasto-Plastic Tie-Rods." International 455 Journal of Architectural Heritage 13(3): 340-357.

456 AS1170.4 (2007). Structural design actions, Part 4: Earthquake actions in Australia., Standards 457 Australia.,

458 Aslam, M., W. G. Godden and D. T. Scalise (1975). Sliding Response of Rigid Bodies to 459 Earthquake Motions. A Report of an Analytical and Experimental Study of the Sliding 460 Response of Rigid Blocks Under Simultaneous Hori zontal and Vertical Earthquake 461 Accelerations. Contract No. W-7405-eng-48. U. S. E. R. a. D. Administration., 
Bao, Y. and D. Konstantinidis (2020). "Dynamics of a sliding- rocking block considering

464 Bathe, K. J. and E. L. Wilson (1976). Numerical methods in finite element analysis. NJ, 465 Prentice-Hall.

466 Benito, B., R. Capote, P. Murphy, J. M. Gaspar-Escribano, J. J. Martinez-Diaz, M. Tsige, D. 467 Stich, J. Garcia-Mayordomo, M. J. Garcia Rodriguez, M. E. Jimenez, J. M. Insua-Arevalo, J. 468 A. Alvarez-Gomez and C. Canora (2007). "An Overview of the Damaging and Low Magnitude 469 Mw 4.8 La Paca Earthquake on 29 January 2005: Context, Seismotectonics, and Seismic Risk 470 Implications for Southeast Spain." Bulletin of the Seismological Society of America 97(3): $471 \quad 671-690$.

472 Bruneau, M. (1994). "State-of-the-Art Report on Seismic Performance of Unreinforced 473 Masonry Buildings." Journal of Structural Engineering, 120(1): 230-251.

474 Casapulla, C., L. Giresini, L. U. Argiento and A. Maione (2019a). "Nonlinear Static and 475 Dynamic Analysis of Rocking Masonry Corners Using Rigid Macro-Block Modeling." 476 International Journal of Structural Stability and Dynamics, 10.1142/s0219455419501372: 4771950137.

478 Casapulla, C., L. Giresini and P. B. Lourenço (2017). "Rocking and Kinematic Approaches for 479 Rigid Block Analysis of Masonry Walls: State of the Art and Recent Developments." Buildings $480 \quad 7(3): 69$.

481 Casapulla, C. and A. Maione (2017). "Free Damped Vibrations of Rocking Rigid Blocks as 482 Uniformly Accelerated Motions." International Journal of Structural Stability and Dynamics 483 17(06). 
Francisco Galvez, Luigi Sorrentino, Dmytro Dizhur and Jason M. Ingham

484 Casapulla, C., A. Maione and L. U. Argiento (2019b). "Performance-Based Seismic Analysis

485 of Rocking Masonry Façades Using Non-Linear Kinematics with Frictional Resistances: A 486 Case Study." International Journal of $\quad$ Architectural Heritage, $487 \quad 10.1080 / 15583058.2019 .1674944$.

488 Cattari, S., D. Camilletti, G. Magenes, C. F. Manzini, P. Morandi, E. Spacone, F. Cannizzaro, 489 B. Calderoni, G. Camata, C. Marano, G. Occhipinti and A. E. S. Cordasco (2018). A 490 Comparative Study On a 2-Storey Benchmark Case Study Through Nonlinear Seismic 491 Analysis. 16th European Conference on Earthquake Engineering. Thessaloniki, Greece,

492 Degli Abbati, S., S. Cattari and S. Lagomarsino (2018). "Theoretically-based and practice493 oriented formulations for the floor spectra evaluation." Earthquakes and Structures 15(5): 565494581.

495 DeJong, M. J. (2009). Seismic Assessment Strategies for Masonry Structures. Doctor of 496 Philosophy in Architecture: Building Technology. PhD Dissertation, MASSACHUSETTS 497 INSTITUTE OF TECHNOLOGY.

498 Derakhshan, H., D. Y. Dizhur, M. C. Griffith and J. M. Ingham (2014). "Seismic Assessment 499 of Out-of-plane Loaded Unreinforced Masonry Walls in Multi-Storey Buildings." Bulletin of 500 the New Zealand Society for Earthquake Engineering 47(2): 120-138.

501 Dimitri, R., L. De Lorenzis and G. Zavarise (2011). "Numerical study on the dynamic behavior 502 of masonry columns and arches on buttresses with the discrete element method." Engineering 503 Structures 33(12): 3172-3188.

504 Dizhur, D., N. Ismail, C. Knox, R. Lumantarna and J. M. Ingham (2010). "Performance of 505 Unreinforced and Retrofitted Masonry Buildings During the 2010 Darfield Earthquake." 506 Bulletin of the New Zealand Society for Earthquake Engineering 43(4): 321-339. 
507 ElGawady, M. A., Q. Ma, J. W. Butterworth and J. Ingham (2011). "Effects of interface

508 material on the performance of free rocking blocks." Earthquake Engineering \& Structural

509 Dynamics 40(4): 375-392.

510 Eurocode 8 (2004). Design of structures for earthquake resistance. Part 1: General rules,

511 seismic actions and rules for buildings. Brussels, Belgium: CEN., European Committee for

512 Standardization,

513 Galvez, F., S. Segatta, M. Giaretton, K. Q. Walsh, I. Giongo and D. Dizhur (2018). FE and DE

514 Modelling of Out-Of-Plane Two-Way Bending Behaviour of Unreinforced Masonry Walls.

515 16th European Conference on Earthquake Engineering. Thessaloniki, Greece,

516 Giaretton, M., D. Dizhur and J. M. Ingham (2016). "Dynamic testing of as-built clay brick

517 unreinforced masonry parapets." Engineering Structures 127: 676-685.

518 Giresini, L. (2017). Design Strategy for the Rocking Stability of Horizontally Restrained

519 Masonry Walls. Proceedings of the 6th International Conference on Computational Methods

520 in Structural Dynamics and Earthquake Engineering (COMPDYN 2015),

$521 \quad 10.7712 / 120117.5620 .18188: 2963-2979$

522 Giresini, L., C. Casapulla, R. Denysiuk, J. Matos and M. Sassu (2018). "Fragility curves for 523 free and restrained rocking masonry façades in one-sided motion." Engineering Structures 164: $524 \quad 195-213$.

525 Giresini, L., M. Fragiacomo and P. B. Lourenço (2015). "Comparison between rocking analysis 526 and kinematic analysis for the dynamic out-of-plane behavior of masonry walls." Earthquake

527 Engineering \& Structural Dynamics 44(13): 2359-2376. 
528 Giresini, L. and M. Sassu (2016). "Horizontally restrained rocking blocks: evaluation of the 529 role of boundary conditions with static and dynamic approaches." Bulletin of Earthquake $530 \quad$ Engineering 15(1): 385-410.

531 Giresini, L., F. Solarino, O. Paganelli, D. V. Oliveira and M. Froli (2019). "ONE-SIDED

532 rocking analysis of corner mechanisms in masonry structures: Influence of geometry, energy 533 dissipation, boundary conditions." Soil Dynamics and Earthquake Engineering 123: 357-370.

534 Gubana, A. and M. Melotto (2019). "Discrete-element analysis of floor influence on seismic 535 response of masonry structures." Proceedings of the Institution of Civil Engineers - Structures 536 and Buildings, 10.1680/jstbu.19.00099: 1-30.

537 Hess, R. L. (2007). Impacts of a M7.8 Southern San Andreas Earthquake on Unreinforced

538 Masonry (URM) Buildings. The ShakeOut Scenario, Suplemental Study - Unreinforced 539 Masonry (URM) Buildings, United States Geological Survey \& California Geological Survey,

540 Housner, G. W. (1963). "The Behavior of Inverted Pendulum Structures During Earthquakes."

541 Bulletin of the Seismological Society of America 53(2): 403-417s.

542 Ishiyama, Y. (1982). "Motions of Rigid Bodies and Criteria For Overturning by Earthquake

543 Excitations." Earthquake Engineering and Structural Dynamics 10: 635-650.

544 Itasca (2013). 3DEC (3-Dimensional distinct element code). Minneapolis (MN)

545 Jing, L. and O. Stephansson (2007). Explicit Discrete Element Method for Block Systems 546 the Distinct Element Method. Fundamentals of Discrete Element Methods for Rock 547 Engineering. 85: 235-316.

548 Kalliontzis, D., S. Sritharan and A. Schultz (2016). "Improved Coefficient of Restitution 549 Estimation for Free Rocking Members." Journal of Structural Engineering 142(12): 06016002. 
Lagomarsino, S. (2015). "Seismic assessment of rocking masonry structures." $\underline{\text { Bulletin of }}$

$553 \quad$ Earthquake Engineering 13(1): 97-128.

554 Lemos, J. V. and A. Campos Costa (2017). "Simulation of Shake Table Tests on Out-Of-Plane

555 Masonry Buildings. Part (V): Discrete Element Approach." International Journal of

556 Architectural Heritage 11(1): 117-124.

557 Lipo, B. and G. de Felice (2016). Smooth-Rocking Oscillator under Natural Accelerograms.

558 ECCOMAS Congress 2016 - VII European Congress on Computational Methods in Applied

559 Sciences and Engineering. V. P. M. Papadrakakis, G. Stefanou, V. Plevris (eds. Crete Island,

560 Greece,

561 Lipscombe, P. R. and S. Pellegrino (1993). "Free Rocking of Prismatic Blocks." Journal of

562 Engineering Mechanics 119(7): 1387-1410.

563 Lorig, L. J. and R. D. Hart (1993). Block dynamics modeling in support of seismic design.

564 Dynamic Analysis and Design Considerations for High-Level Nuclear Waste Repositories. H.

565 Q. (ed.). New York, ASCE:: 228-242

566 MathWorks (2008). "MATLAB User’s Manual. ."

567 McNeel, R. and Associates (2014). Rhinoceros 5,

568 Menon, A. and G. Magenes (2011). "Definition of Seismic Input for Out-of-Plane Response of

569 Masonry Walls: I. Parametric Study." Journal of Earthquake Engineering 15(2): 165-194. 
576 NZS1170.5 (2004). Structural design actions, Part 5: earthquake actions-New Zealand. NZS

577 1170.5:2004. Standards New Zealand (NZS), Standards New Zealand (NZS) Technical 578 Committee BD-006-04-11, Wellington, New Zealand.,

579 Olcese, S. (2018). Use of discrete element modelling for the seismic assessment of a benchmark 580 case study masonry structure. Corso di Laurea in Ingegneria Edile - Architettura. Master 581 Thesis, Università degli Studi di Genova.

582 Papantonopoulos, C., I. N. Psycharis, D. Y. Papastamatiou, J. V. Lemos and H. P. Mouzakis 583 (2002). "Numerical prediction of the earthquake response of classical columns using the 584 distinct element method." Earthquake Engineering \& Structural Dynamics 31(9): 1699-1717.

585 Priestley, M. J. N. (1985). "Seismic Behaviour of Unreinforced Masonry Walls." Bulletin of 586 The New Zealand National Society for Earthquake Engineering 18(2).

587 Psycharis, I. N. and P. C. Jennings (1983). "Rocking of Slender Rigid Bodies Allowed to 588 Uplift." Earthquake Engineering and Structural Dynamics 11: 57-76.

589 Psycharis, I. N., J. V. Lemos, D. Y. Papastamatiou, C. Zambas and C. Papantonopoulos (2003).

590 "Numerical study of the seismic behaviour of a part of the Parthenon Pronaos." Earthquake

$591 \quad$ Engineering \& Structural Dynamics 32(13): 2063-2084. 
592 Pulatsu, B., F. Gencer and E. Erdogmus (2020). "Study of the effect of construction techniques on the seismic capacity of ancient dry-joint masonry towers through DEM." European Journal of Environmental and Civil Engineering, 10.1080/19648189.2020.1824823: 1-18. Against Rigid Walls." 47: 323-334.

600 Sorrentino, L., O. AlShawa and L. D. Decanini (2011). "The relevance of energy damping in unreinforced masonry rocking mechanisms. Experimental and analytic investigations." Bulletin of Earthquake Engineering 9(5): 1617-1642.

603 Sorrentino, L., S. Kunnath, G. Monti and G. Scalora (2008). "Seismically induced one-sided 604 rocking response of unreinforced masonry façades." Engineering Structures 30(8): 2140-2153. of Earthquake Engineering 15(5): 2305-2319.

607 Tomassetti, U., F. Graziotti, L. Sorrentino and A. Penna (2019). "Modelling rocking response 608 via equivalent viscous damping." Earthquake Engineering \& Structural Dynamics, 10.1002/eqe.3182.

610

611

612

613

614

615 
616

617 Table 1: Selected ground motions

\begin{tabular}{|c|c|c|c|c|c|c|c|c|}
\hline Event - Station (Component) & Date & $\mathrm{M}_{\mathrm{w}}$ & $D[\mathrm{~km}]$ & $\begin{array}{c}\text { Soil } \\
\text { Type }\end{array}$ & $\begin{array}{l}\text { PGA } \\
{[\mathrm{g}]}\end{array}$ & $\begin{array}{c}\text { PGV } \\
{[\mathrm{cm} / \mathrm{s}]}\end{array}$ & PGD $[\mathrm{cm}]$ & $\Delta t[\mathrm{~s}]$ \\
\hline $\begin{array}{l}\text { Bucarest, Romania - Building } \\
\text { Research Institute (BUCAR0) }\end{array}$ & March/4/1977 & 7.5 & 150 & $\mathrm{D}$ & 0.21 & 73.6 & 24.4 & 16.2 \\
\hline $\begin{array}{l}\text { Northridge, CA, USA - Rinaldi } \\
\text { Receiving Station (RRS228) }\end{array}$ & January/17/1994 & 6.7 & 0.1 & $\mathrm{C}$ & 0.84 & 166.1 & 28.8 & 14.9 \\
\hline $\begin{array}{l}\text { Nahanni, Canada - Site } 1 \\
\text { (1ST280) }\end{array}$ & December/23/1985 & 6.8 & 0.1 & A & 1.1 & 46.1 & 14.6 & 20.5 \\
\hline $\begin{array}{l}\text { Christchurch, NZ - Heathcote } \\
\text { Valley School (HVSC1) }\end{array}$ & February/22/2011 & 6.3 & 4 & $\mathrm{C}$ & 1.58 & 106.6 & 21.77 & 29.0 \\
\hline $\begin{array}{l}M_{W}=\text { Moment magnitude } \\
D=\text { Distance from the surface } \mathrm{p}\end{array}$ & ojection of the & \multicolumn{7}{|c|}{$\begin{array}{l}\text { Peak ground: PGA = Acceleration, } \mathrm{PGV}=\text { Velocity, } \mathrm{PGD}= \\
\text { Displacement }\end{array}$} \\
\hline Soil type = According to Euroc & $8(2004)$ & \multicolumn{7}{|c|}{$\Delta t=$ Duration } \\
\hline
\end{tabular}

618

619

620

621

622

623

624

625

626

627

628

629

630

631

632

633

634

635

636

637

638

639

640 
641

642 Table 2: Weighted Mean Error as in equation 10.

\begin{tabular}{|c|c|c|c|c|c|c|c|c|c|c|}
\hline & \multicolumn{2}{|c|}{ SDOF } & \multicolumn{2}{|c|}{ 2DOF } & \multicolumn{2}{|c|}{ 3DOF } & \multicolumn{2}{|c|}{ 4DOF } & \multicolumn{2}{|c|}{ 5DOF } \\
\hline & BUCAR0 & RRS228 & BUCAR0 & RRS228 & BUCAR0 & RRS228 & BUCAR0 & RRS228 & BUCAR0 & RRS228 \\
\hline $\begin{array}{l}\text { Acceleration Top } \\
\text { Response }\end{array}$ & 0.344 & 0.407 & 0.309 & 0.343 & 0.305 & 0.331 & 0.298 & 0.326 & 0.292 & 0.323 \\
\hline Response Spectra & 0.140 & 0.152 & 0.082 & 0.093 & 0.063 & 0.074 & 0.056 & 0.066 & 0.062 & 0.062 \\
\hline Power Spectra & 0.273 & 0.231 & 0.160 & 0.141 & 0.133 & 0.117 & 0.119 & 0.108 & 0.129 & 0.105 \\
\hline
\end{tabular}

643 


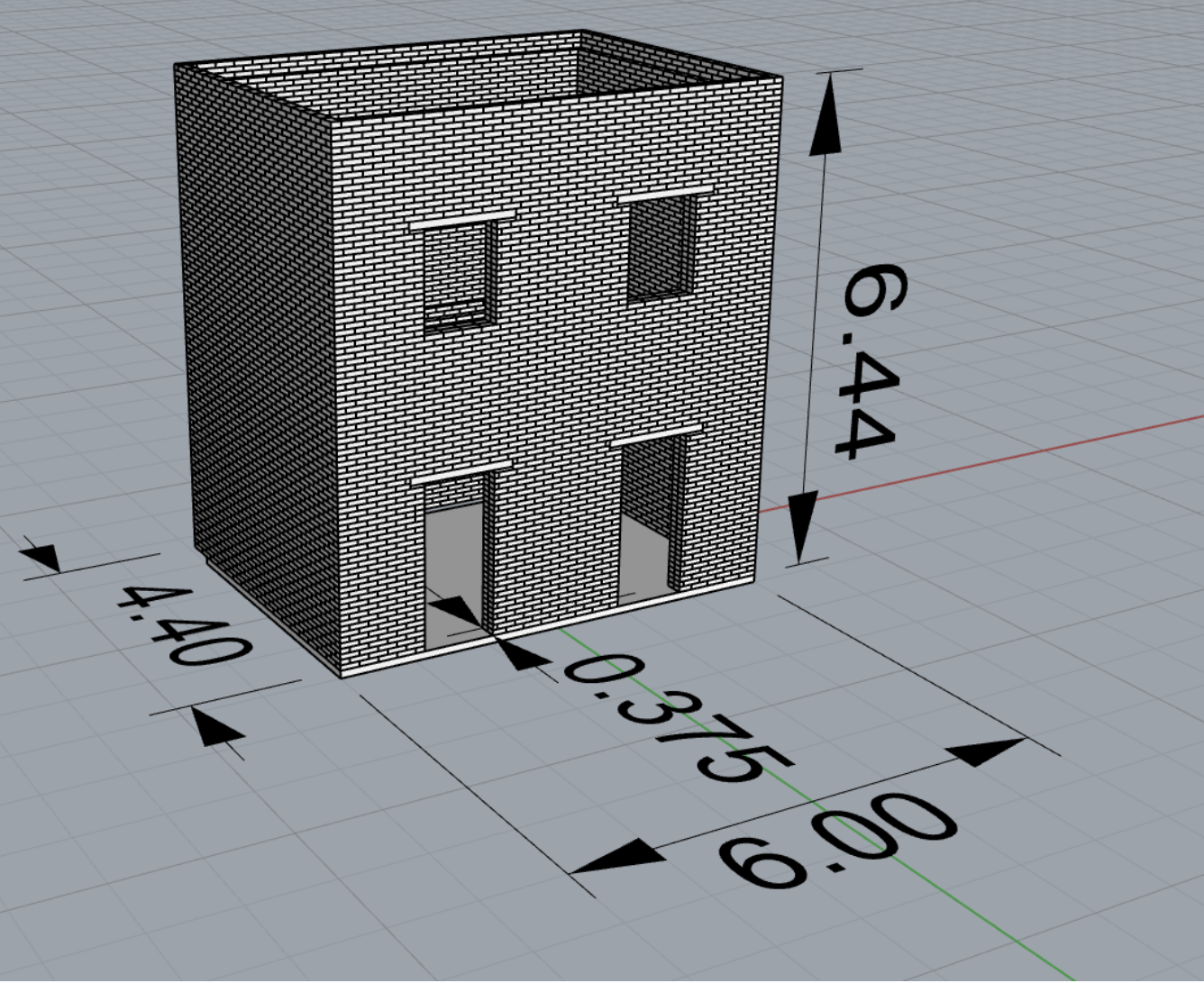

(a) Rhinoceros ${ }^{\circledR}$ (Dimensions in $\left.\mathrm{m}\right)$

Figure 1: Geometrical model of the two-storey case study building 


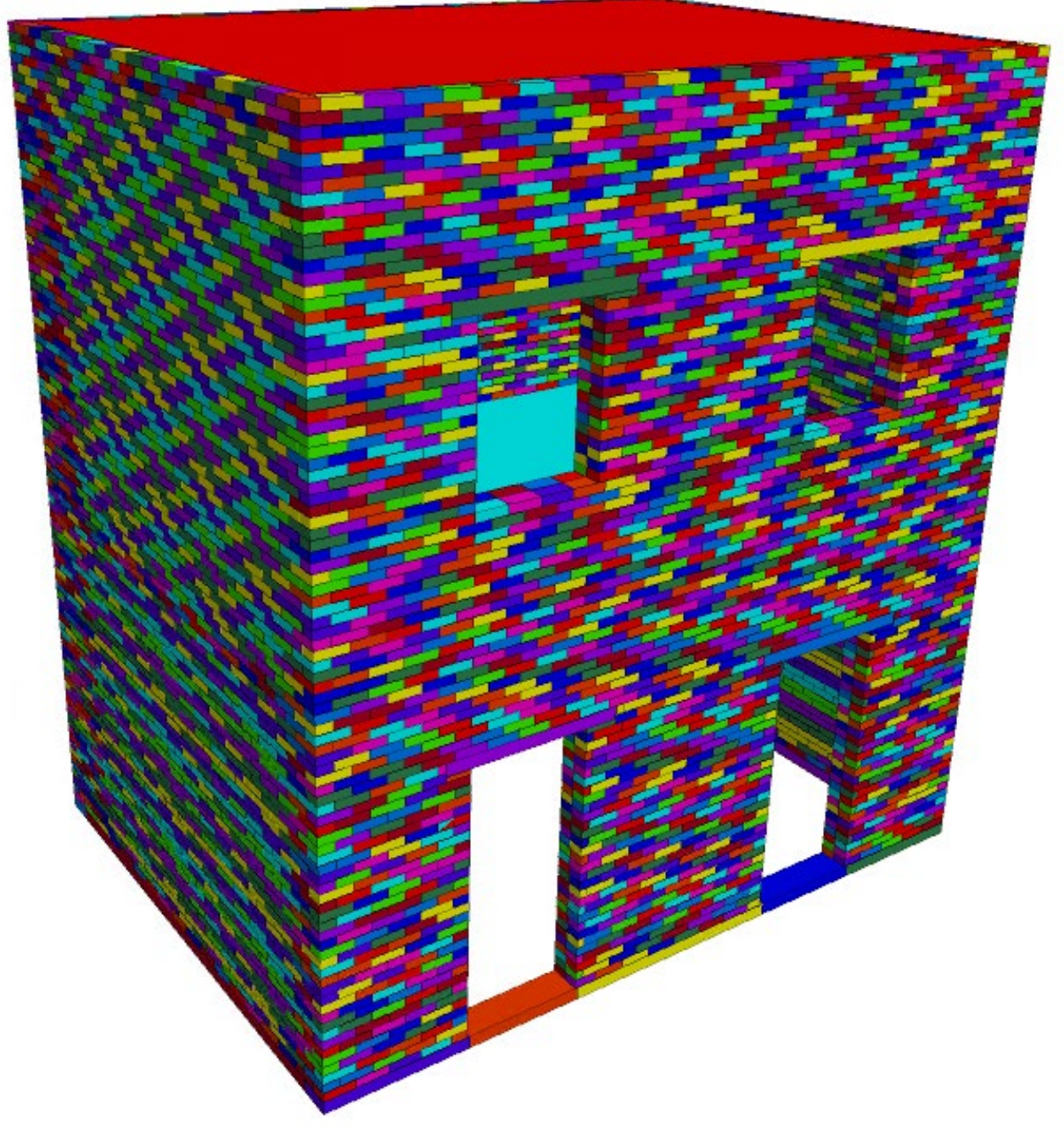

(b) DEM

Figure 1: Geometrical model of the two-storey case study building 


\section{Displacement [mm]}
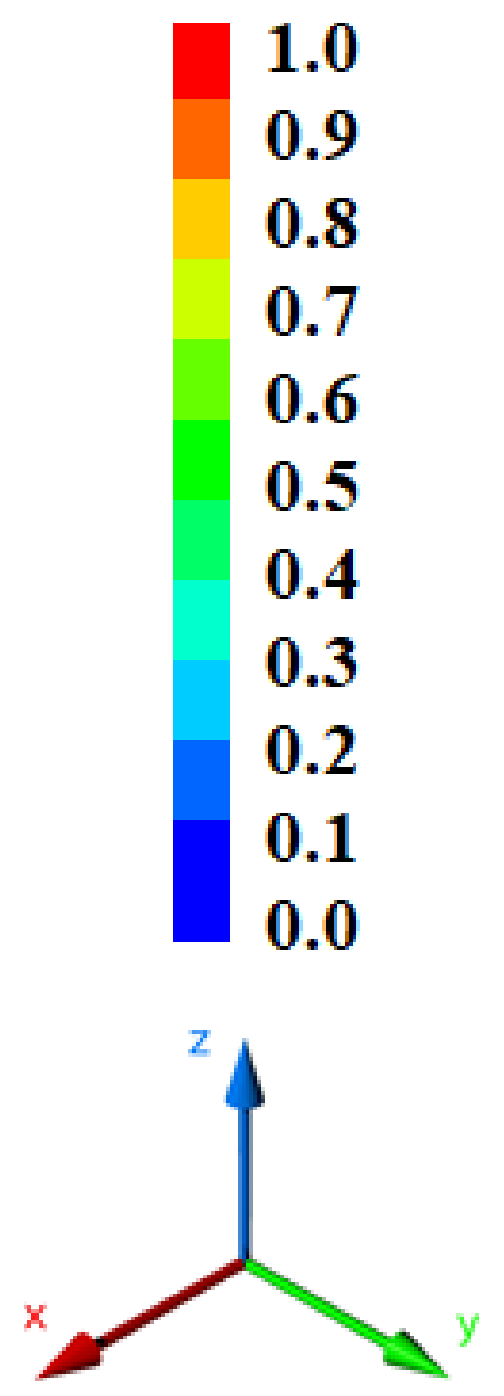

Figure 2: First and second modal shapes and periods in the $Y$ direction of the complete and the simplified structure calculated using DEM modal analysis 


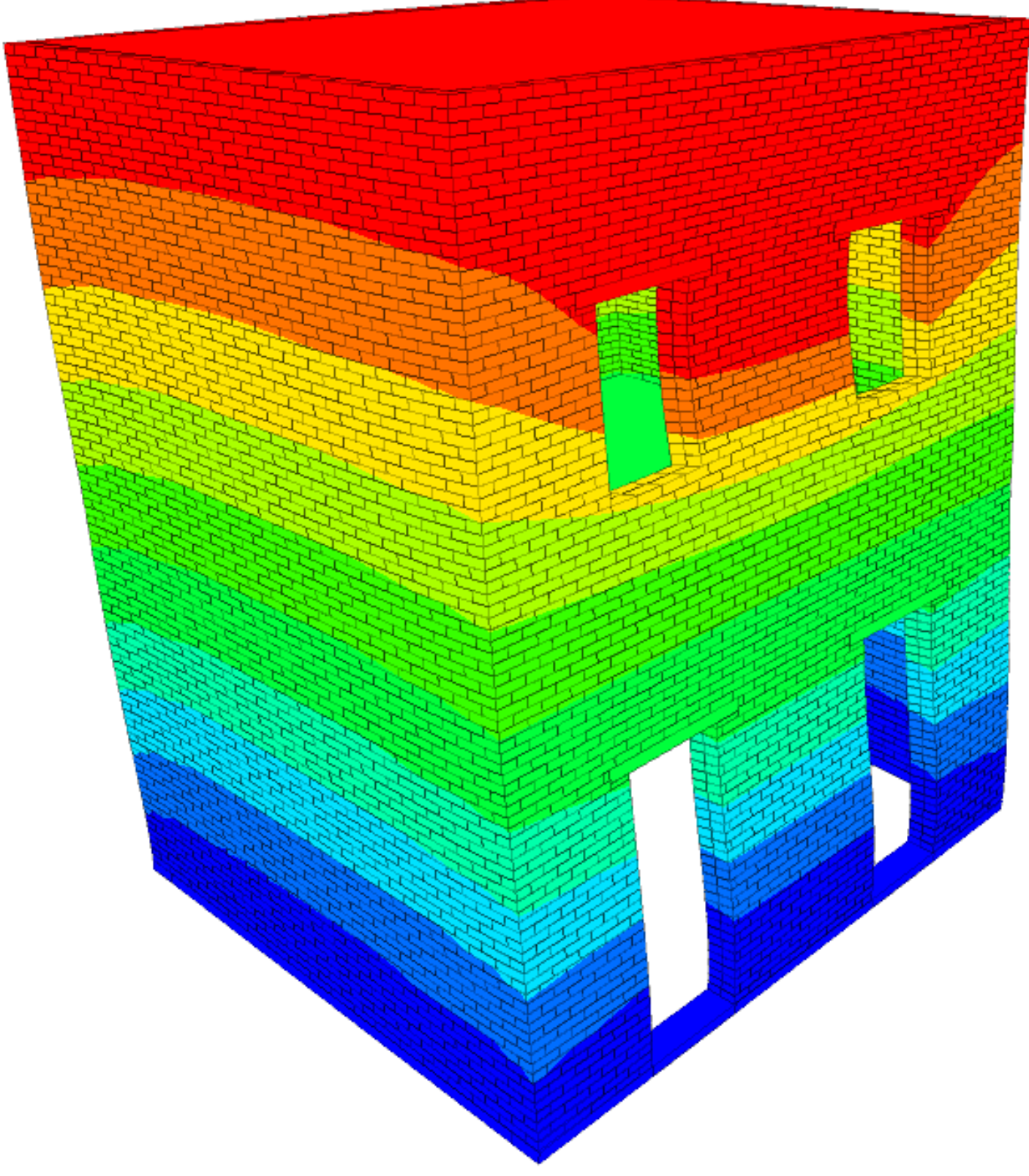

(a) 1 st mode of CBDEM ( $\mathrm{T}=0.25 \mathrm{~s})$

Figure 2: First and second modal shapes and periods in the $Y$ direction of the complete and the simplified structure calculated using DEM modal analysis 


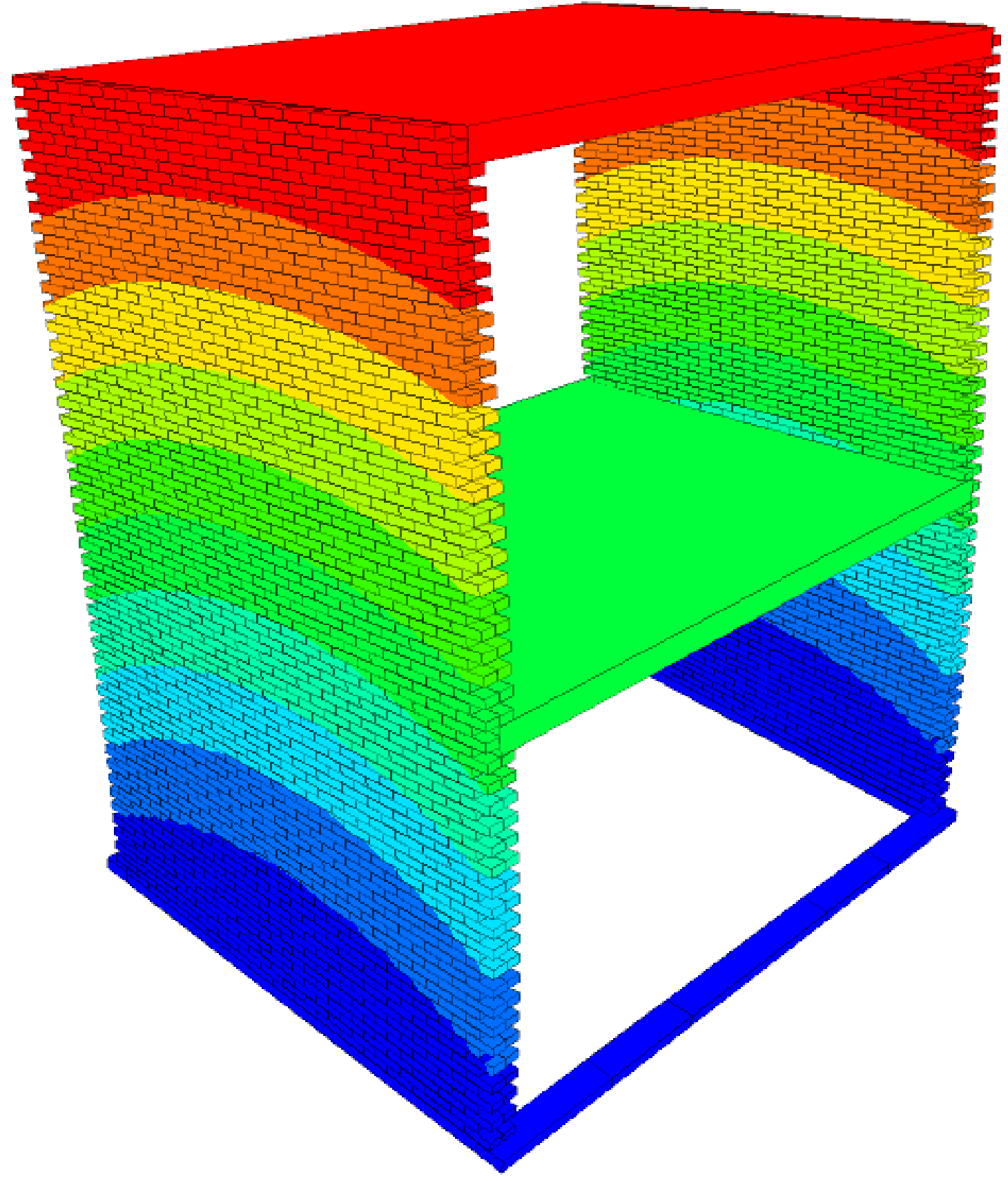

(b) $1 \mathrm{st}$ mode of SBDEM ( $\mathrm{T}=0.27 \mathrm{~s})$

Figure 2: First and second modal shapes and periods in the $Y$ direction of the complete and the simplified structure calculated using DEM modal analysis 


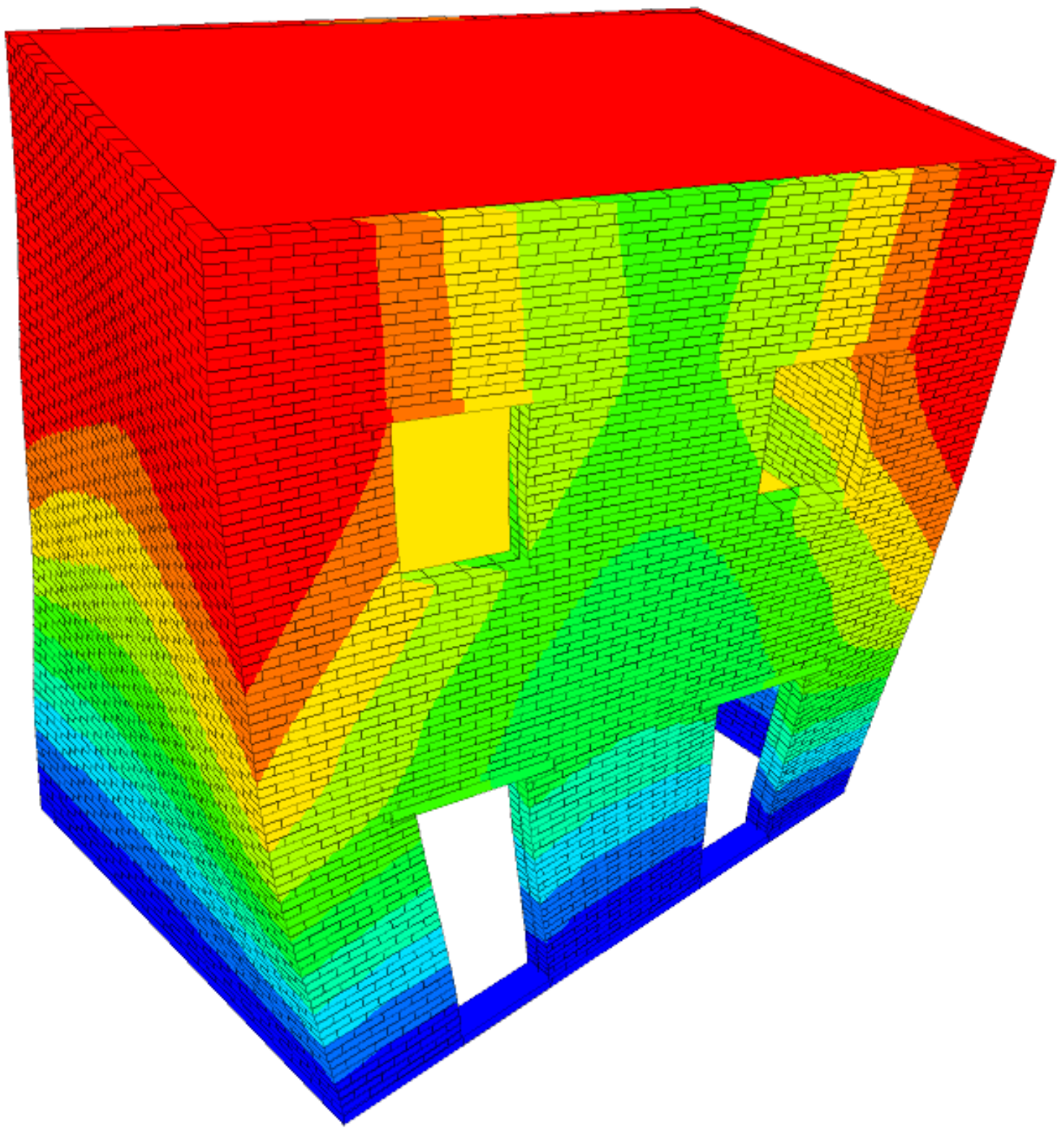

(c) 2nd mode of CBDEM ( $\mathrm{T}=0.16 \mathrm{~s}$ )

Figure 2: First and second modal shapes and periods in the $Y$ direction of the complete and the simplified structure calculated using DEM modal analysis 


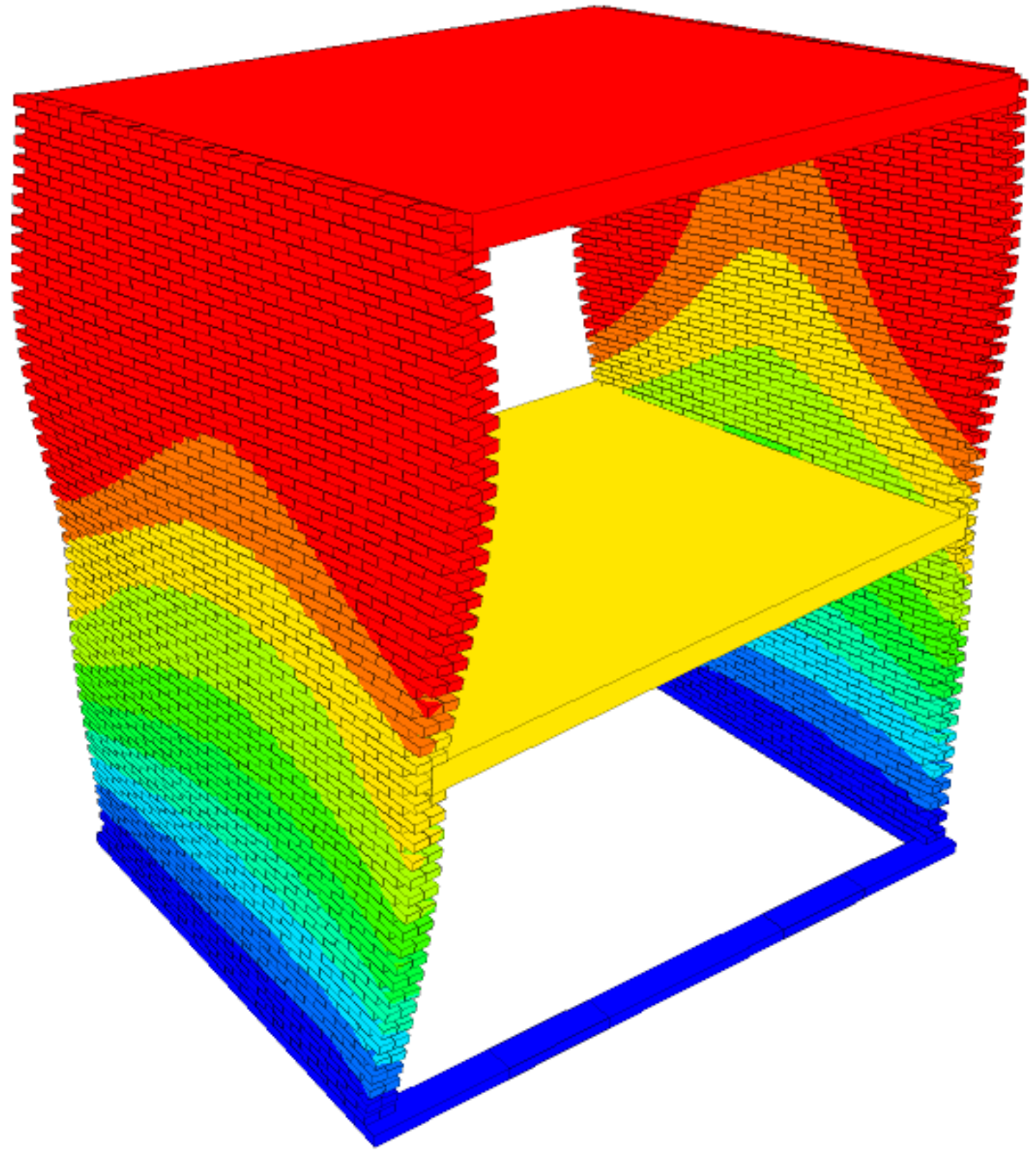

(d) 2nd mode of SBDEM ( $\mathrm{T}=0.17 \mathrm{~s})$

Figure 2: First and second modal shapes and periods in the $Y$ direction of the complete and the simplified structure calculated using DEM modal analysis 


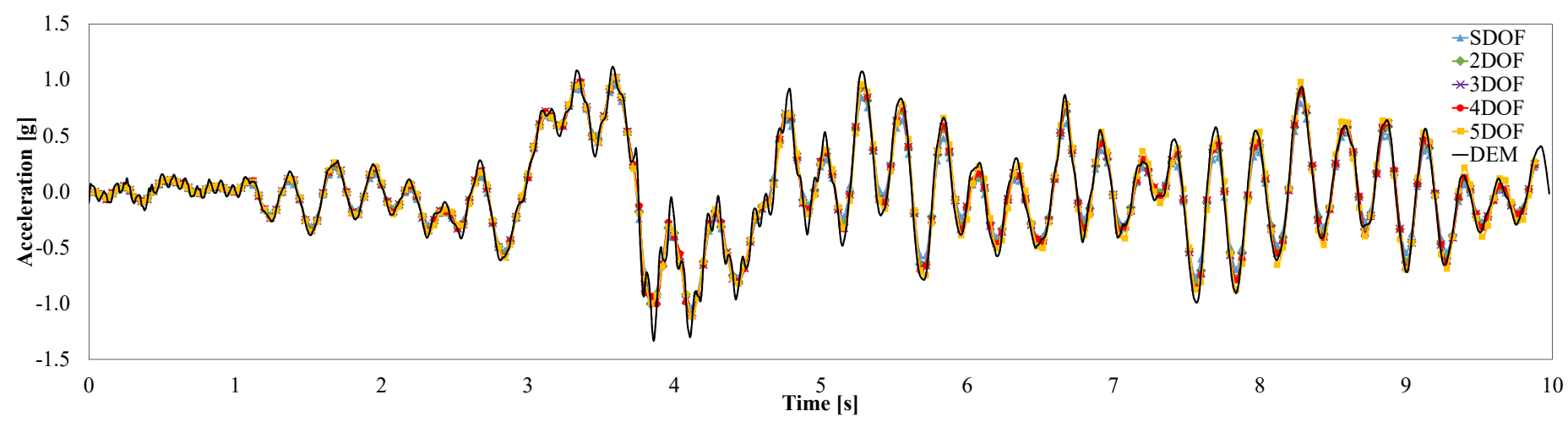

(a) Time-history response

Figure 3: Comparison between the seismic response of the SBDEM and SMDOF for BUCAR0 earthquake. 


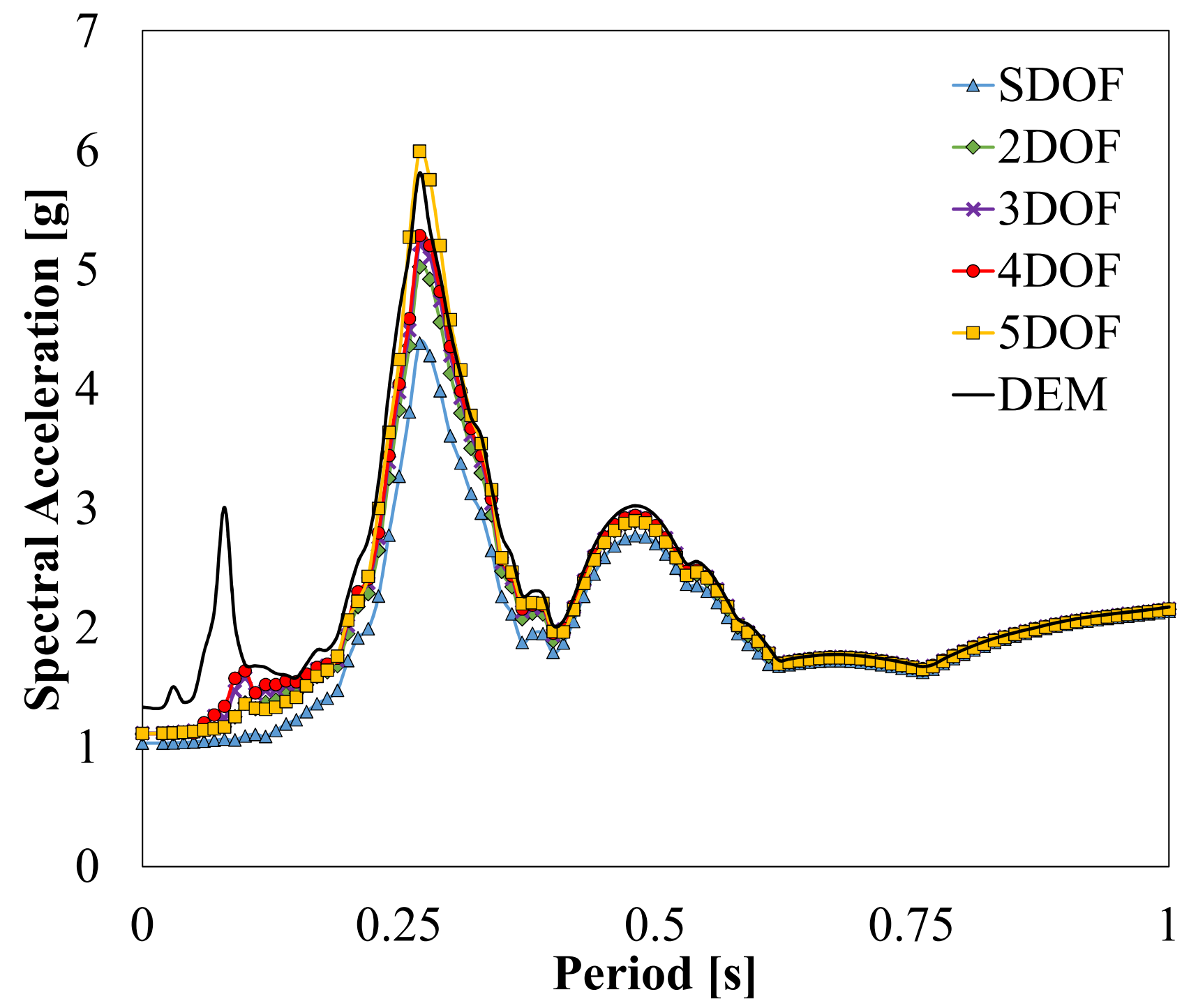

(b) Response Spectra

Figure 3: Comparison between the seismic response of the SBDEM and SMDOF for BUCAR0 earthquake. 


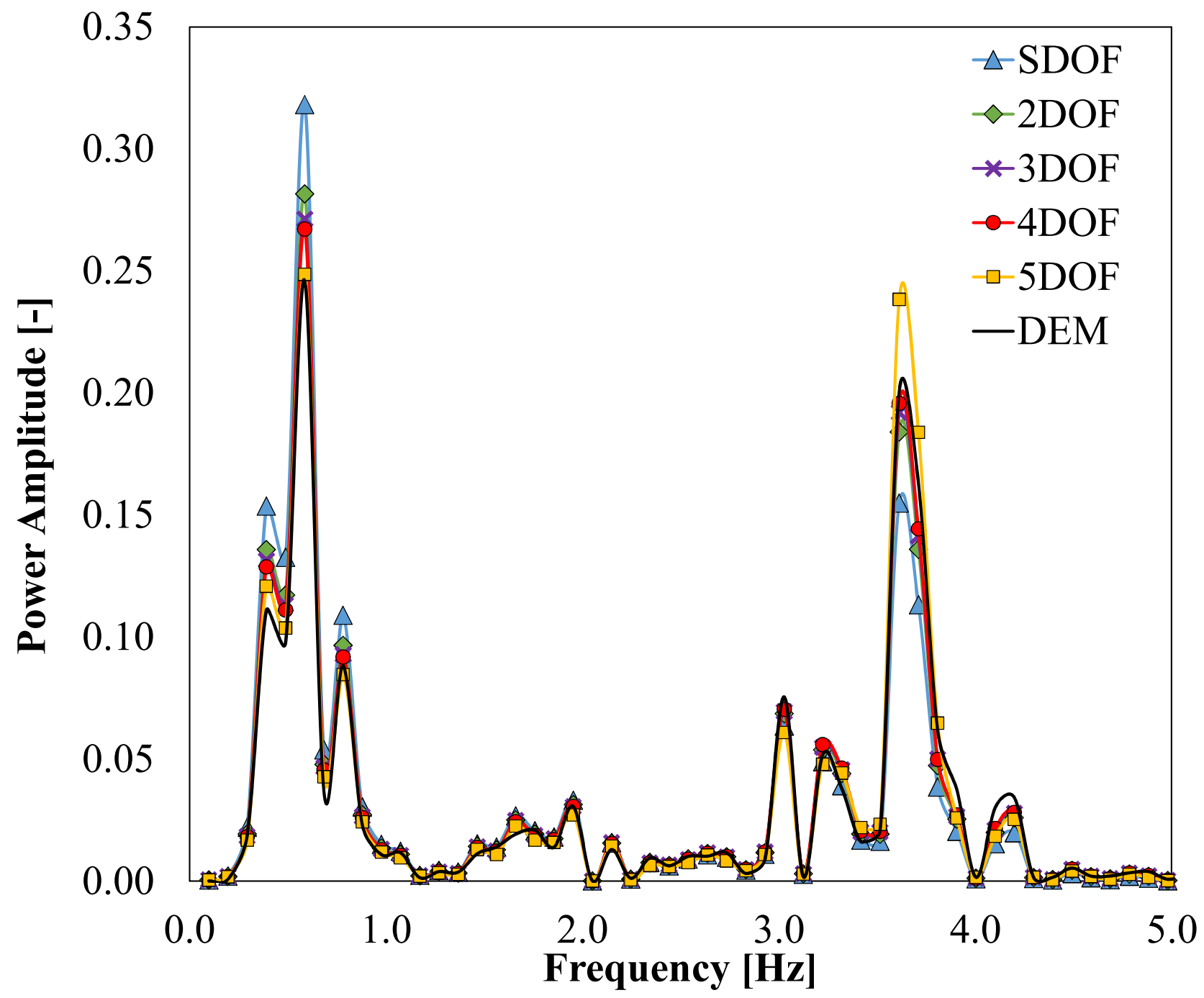

(c) Power Spectra

Figure 3: Comparison between the seismic response of the SBDEM and SMDOF for BUCAR0 earthquake. 


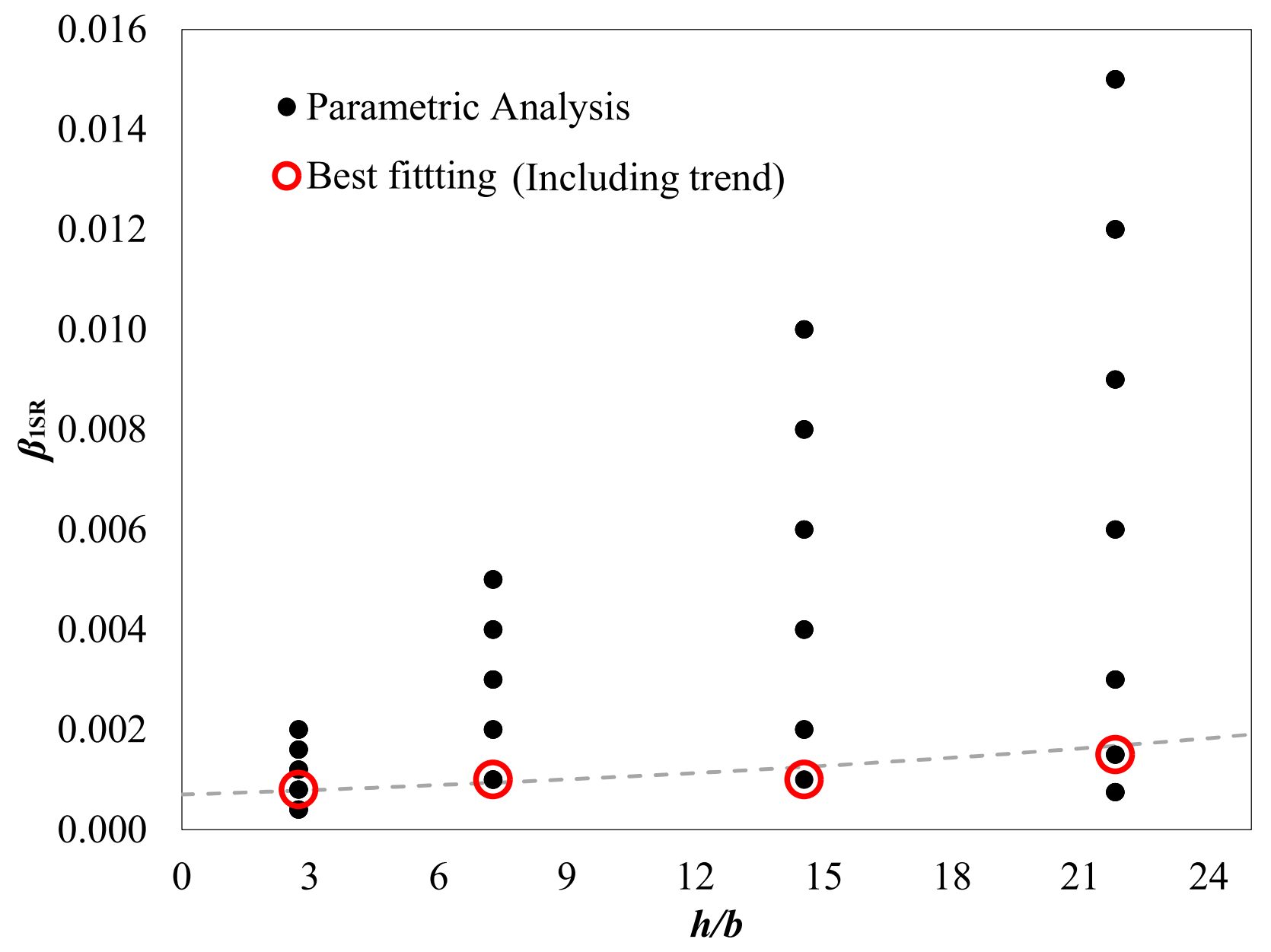

(a) Values of $\beta_{1 \mathrm{SR}}$ for walls with $b=0.11 \mathrm{~m}, E=1800 \mathrm{MPa}$ and different values of $h / b$.

Figure 4: Parametric studies. 


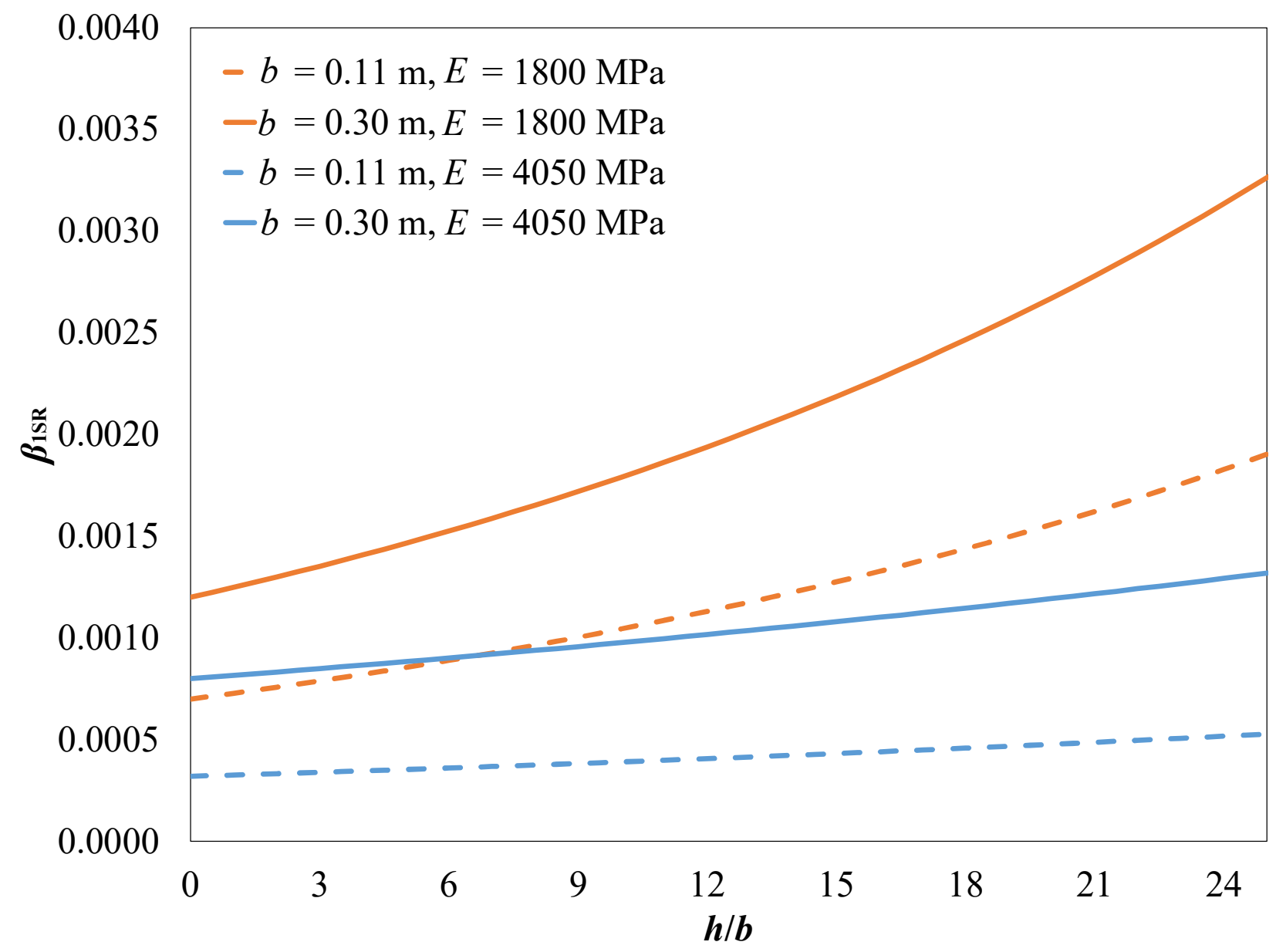

(b) Best fitting $\beta_{1 \mathrm{SR}}$ for different values of $E$ and geometry variations

Figure 4: Parametric studies. 


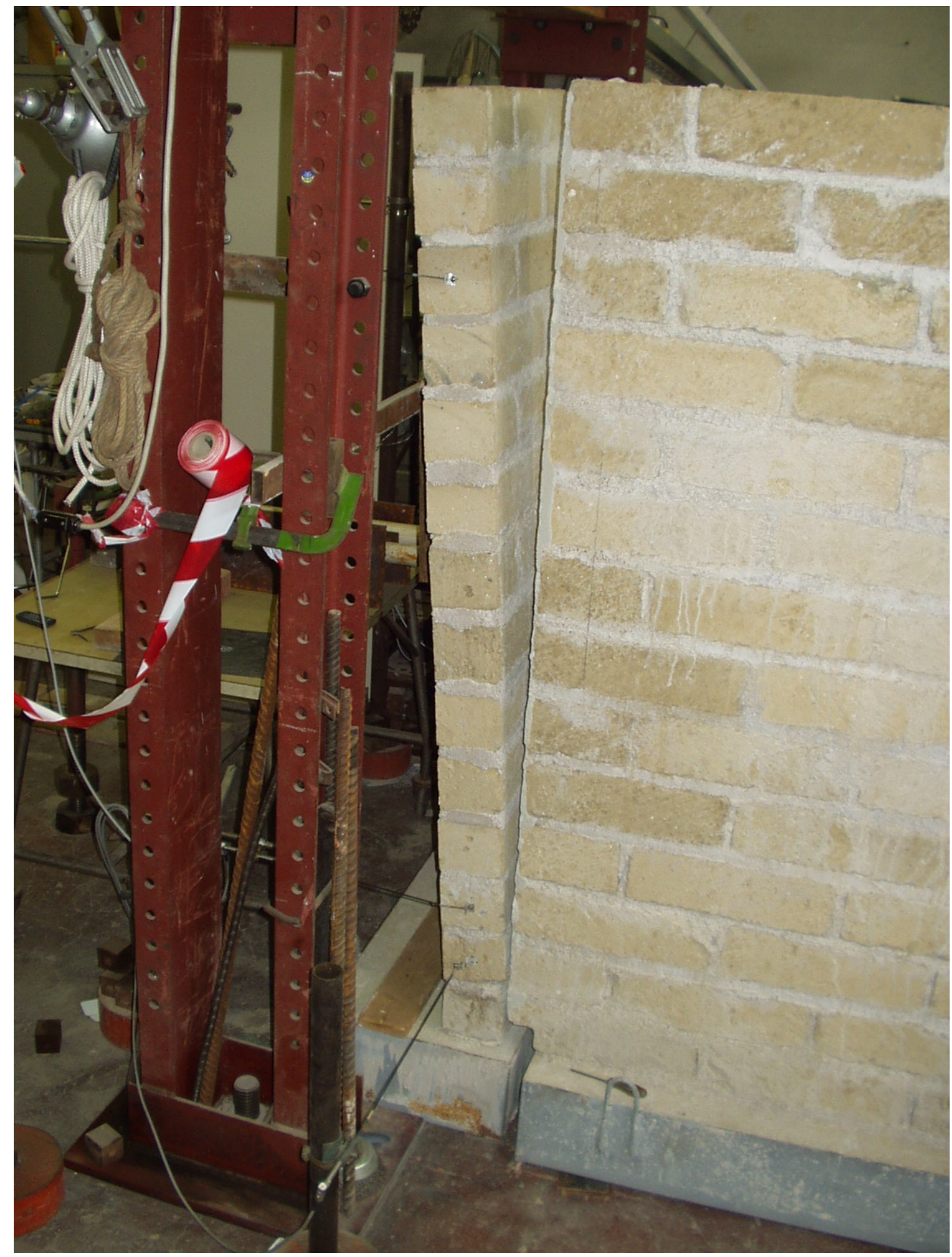

(a) Experimental setup (Sorrentino et al., 2011)

Figure 5: Experimental testing from Sorrentino et al. (2011) and simulations using 3DEC 


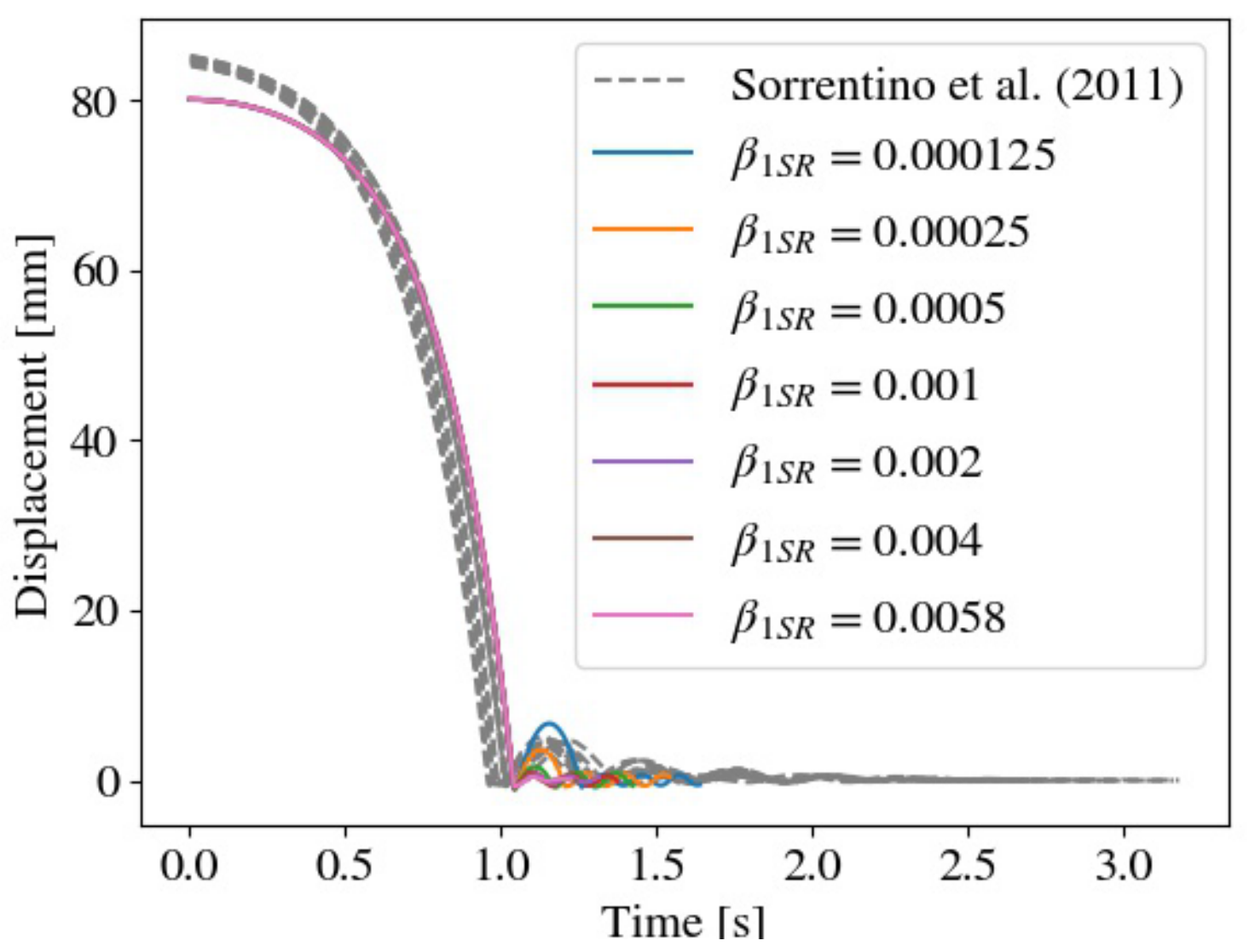

(b) Complete time-history

Figure 5: Experimental testing from Sorrentino et al. (2011) and simulations using 3DEC 


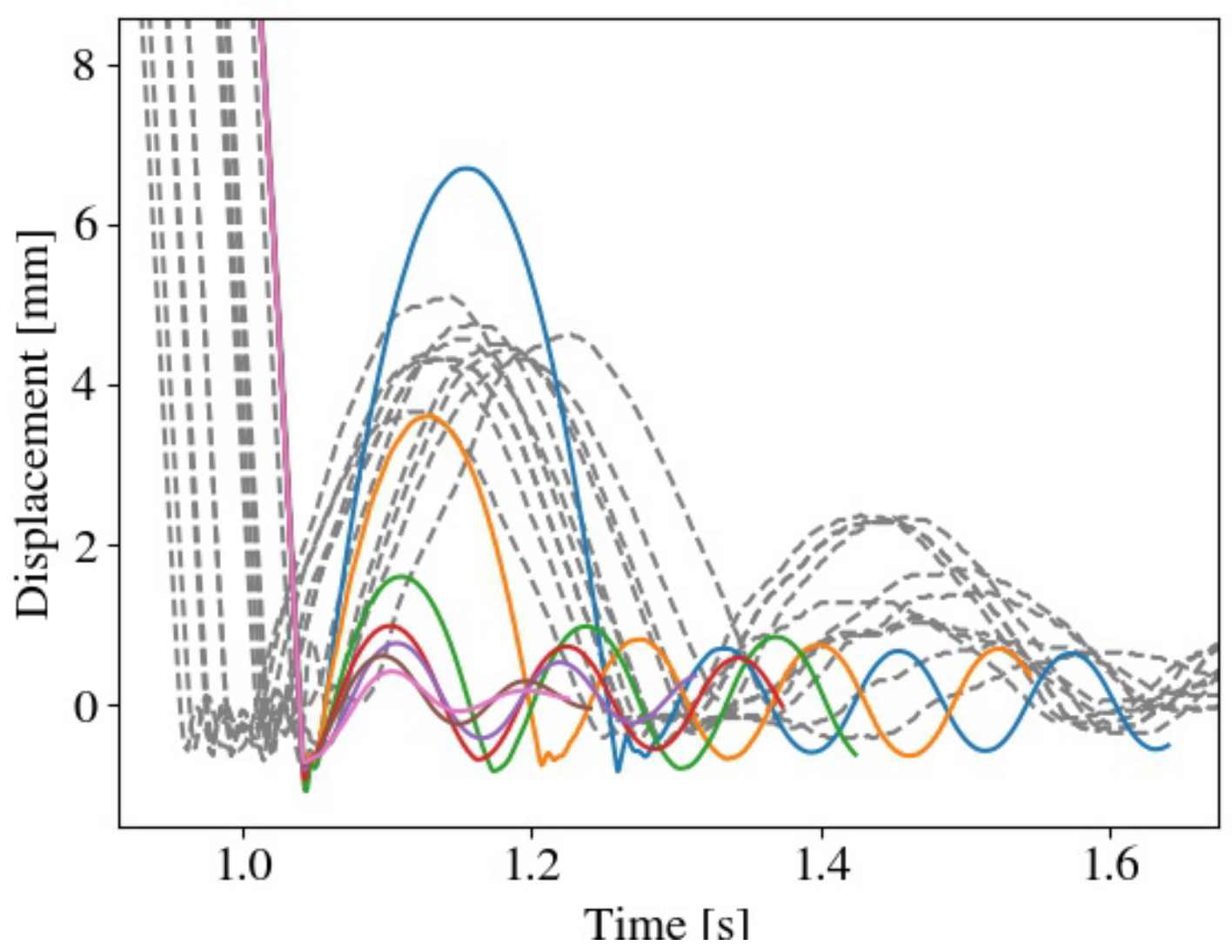

(c) Expanded view between $0.9 \mathrm{~s}$ and $1.9 \mathrm{~s}$

Figure 5: Experimental testing from Sorrentino et al. (2011) and simulations using 3DEC 


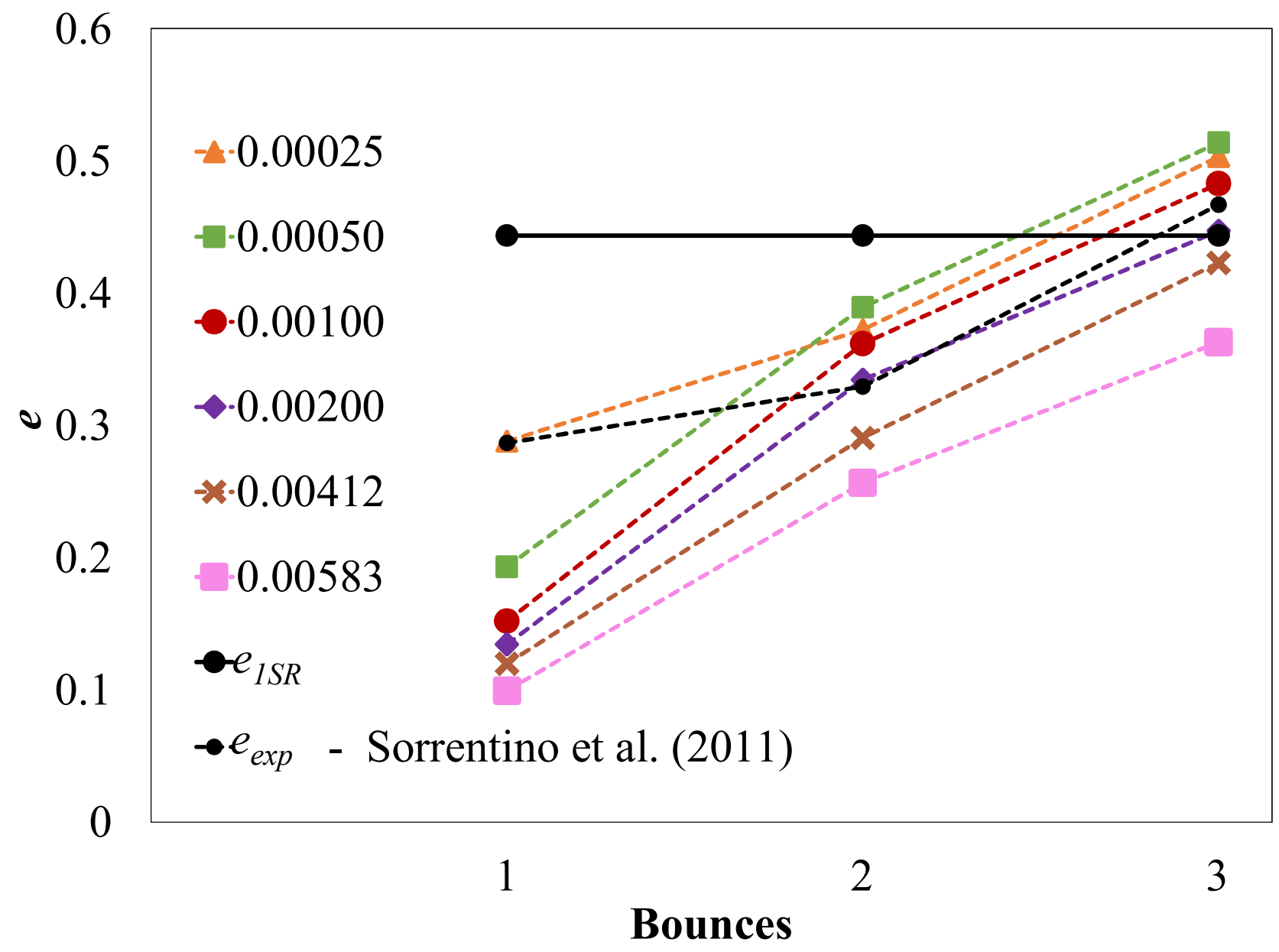

(d) Values of $e_{\text {exp }}$ for different simulations using $\beta_{1 \mathrm{SR}}$ compared to $e_{1 \mathrm{SR}}$ and experimental testing

Figure 5: Experimental testing from Sorrentino et al. (2011) and simulations using 3DEC 


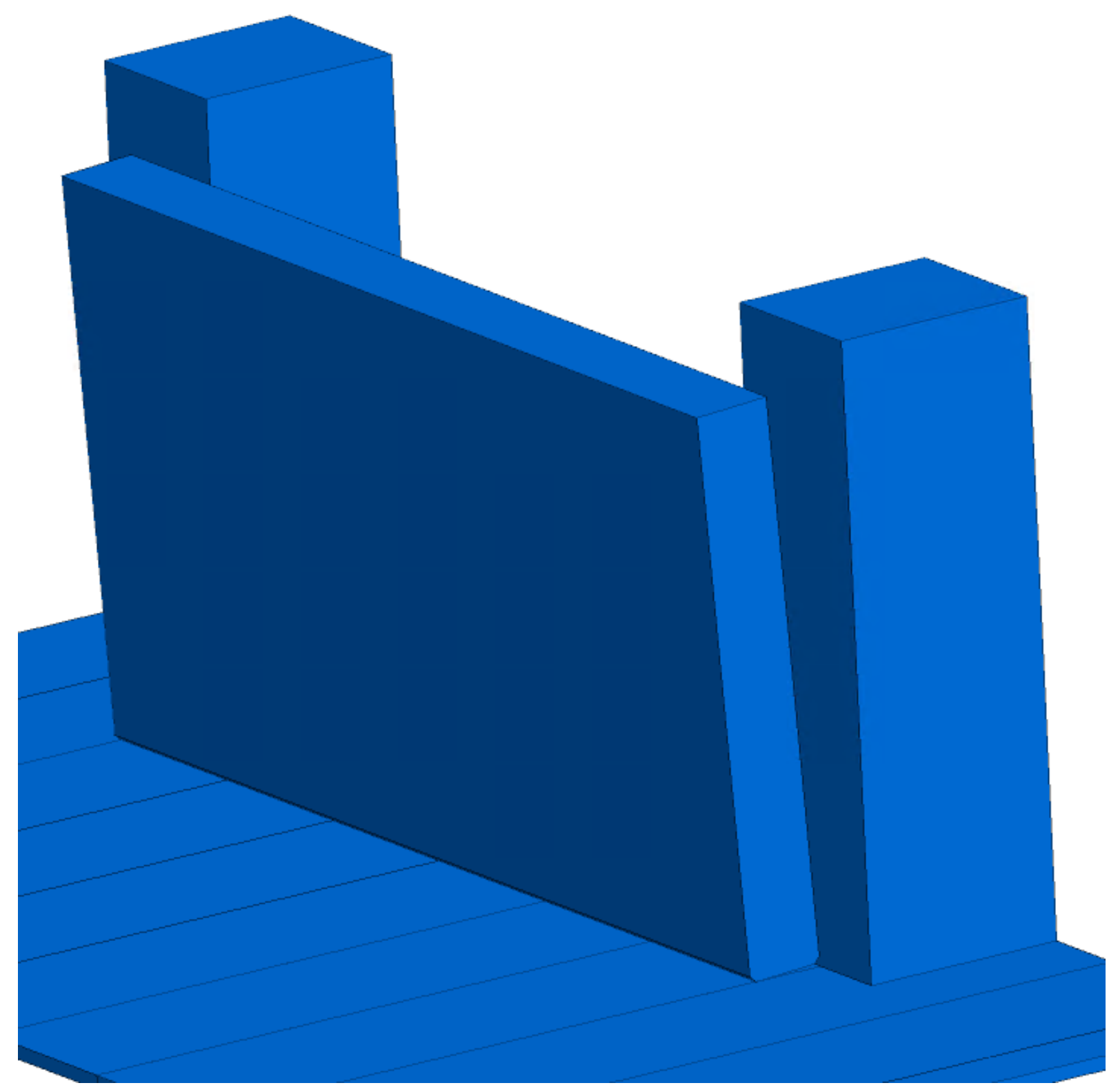

(a) DEM model

Figure 6: Comparison of top displacement between experiments and DEM simulation. 

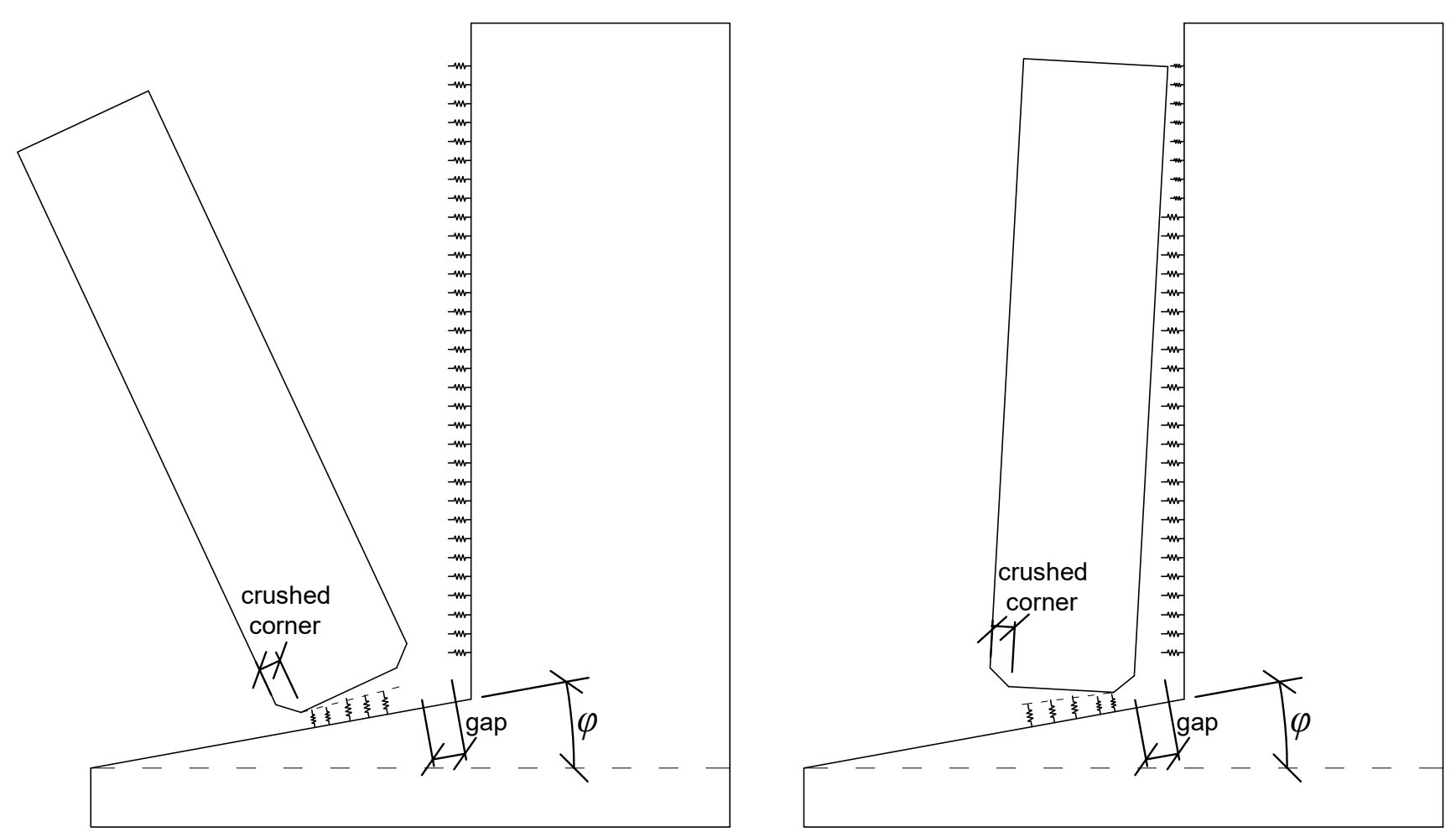

(b) Diagram of tilted rocking facade

Figure 6: Comparison of top displacement between experiments and DEM simulation. 


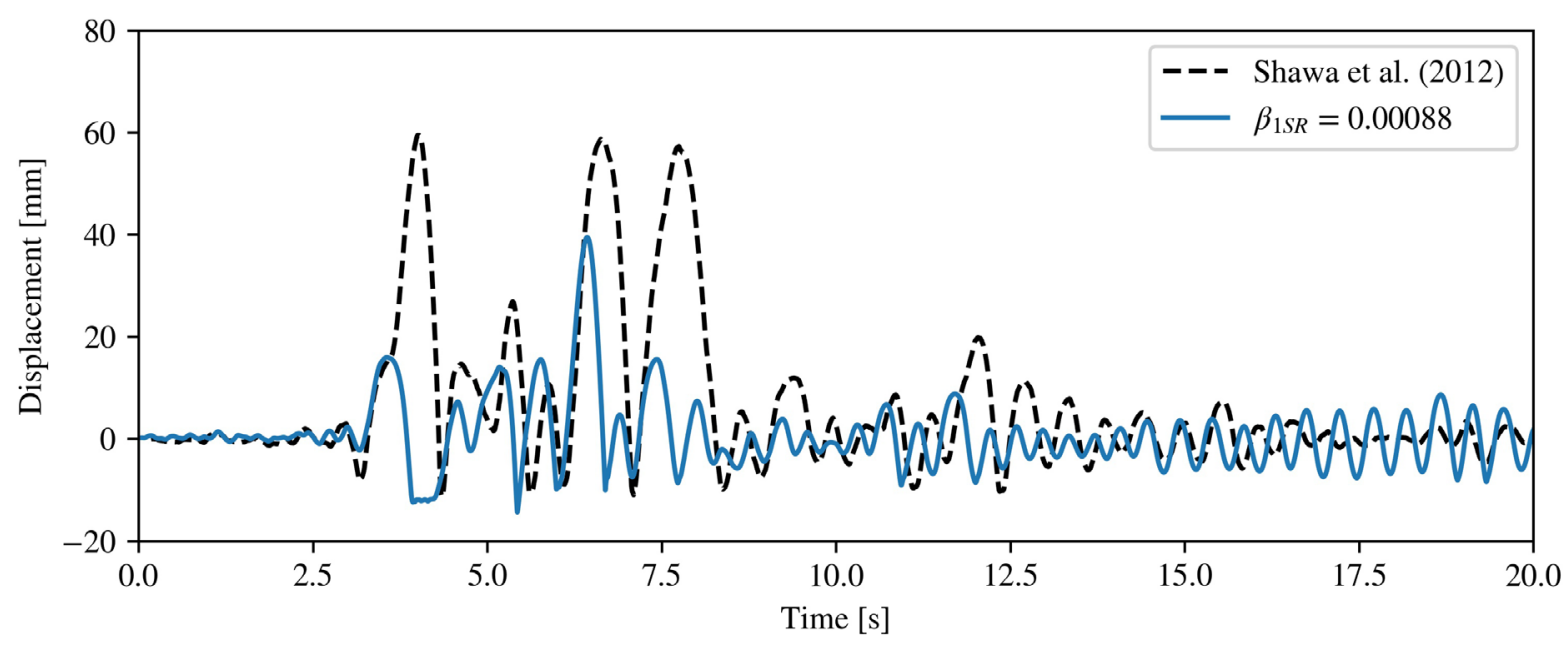

(c) BagnirWE, $\varphi=0.191^{\circ}$

Figure 6: Comparison of top displacement between experiments and DEM simulation. 


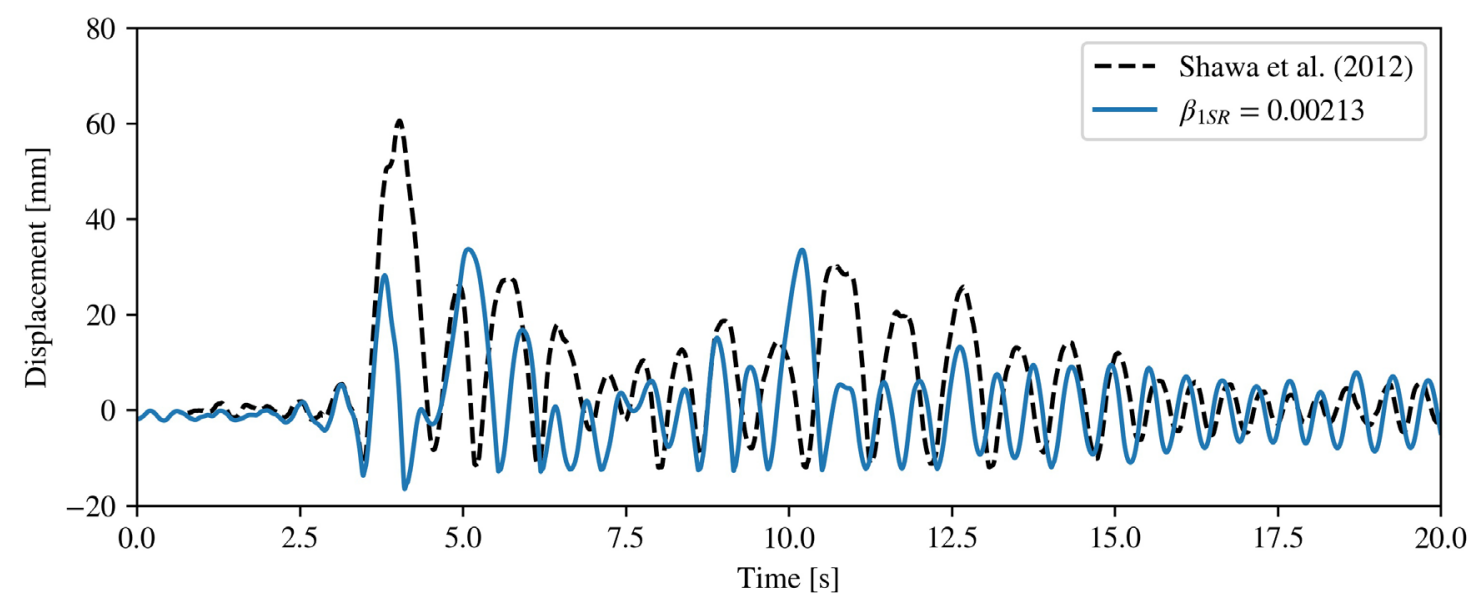

(d) SturWE, $\varphi=0.210^{\circ}$

Figure 6: Comparison of top displacement between experiments and DEM simulation. 


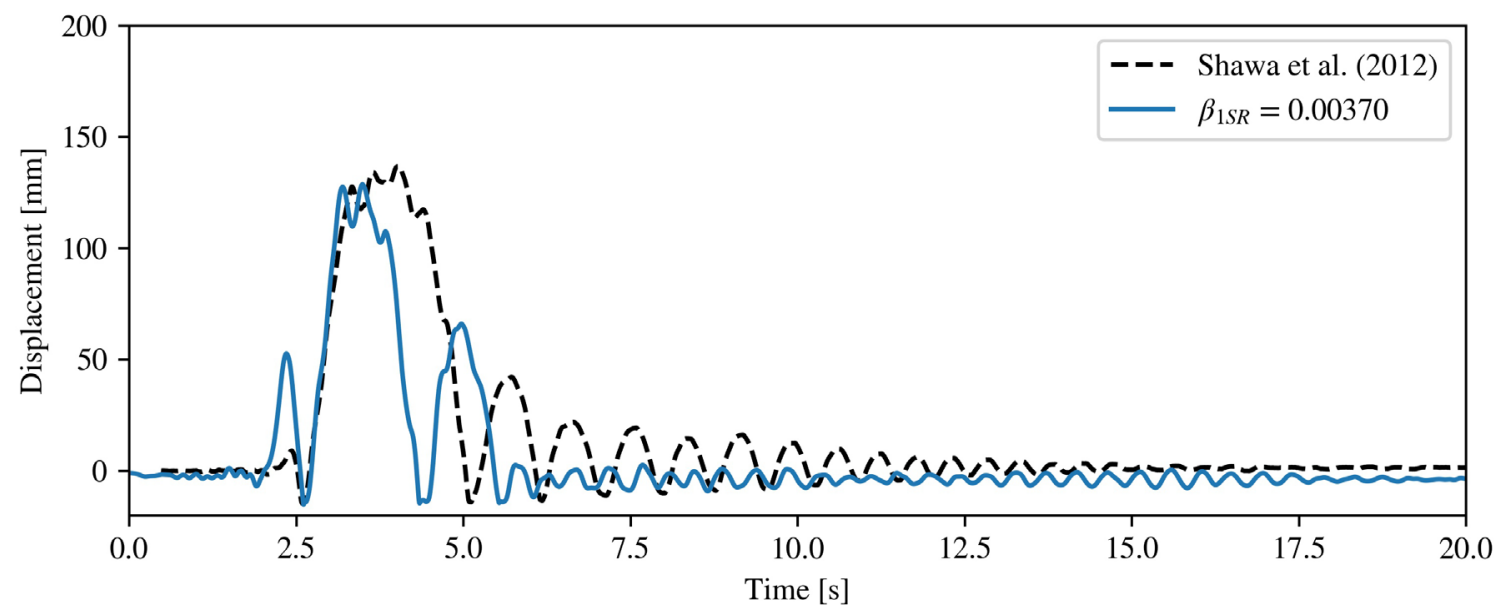

(e) R1168EW, $\varphi=0.272^{\circ}$

Figure 6: Comparison of top displacement between experiments and DEM simulation. 


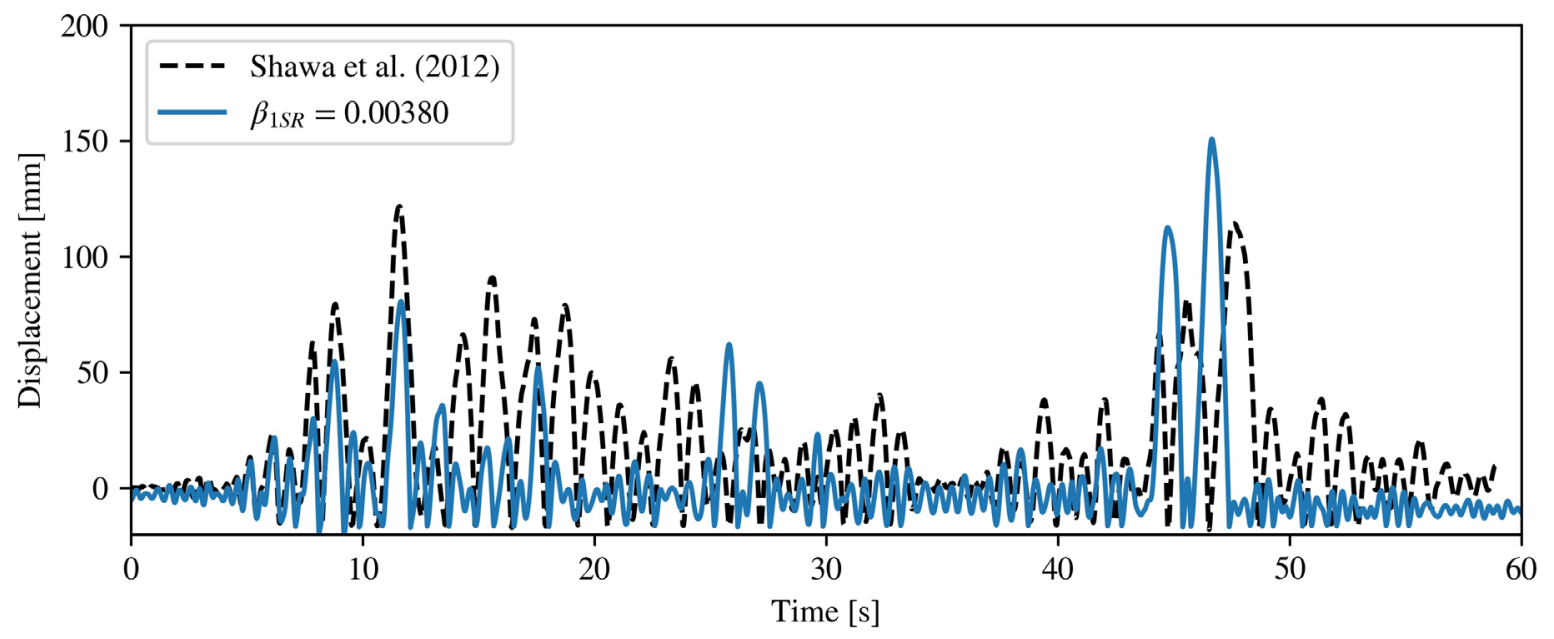

(f) CalitWE, $\varphi=0.348^{\circ}$

Figure 6: Comparison of top displacement between experiments and DEM simulation. 


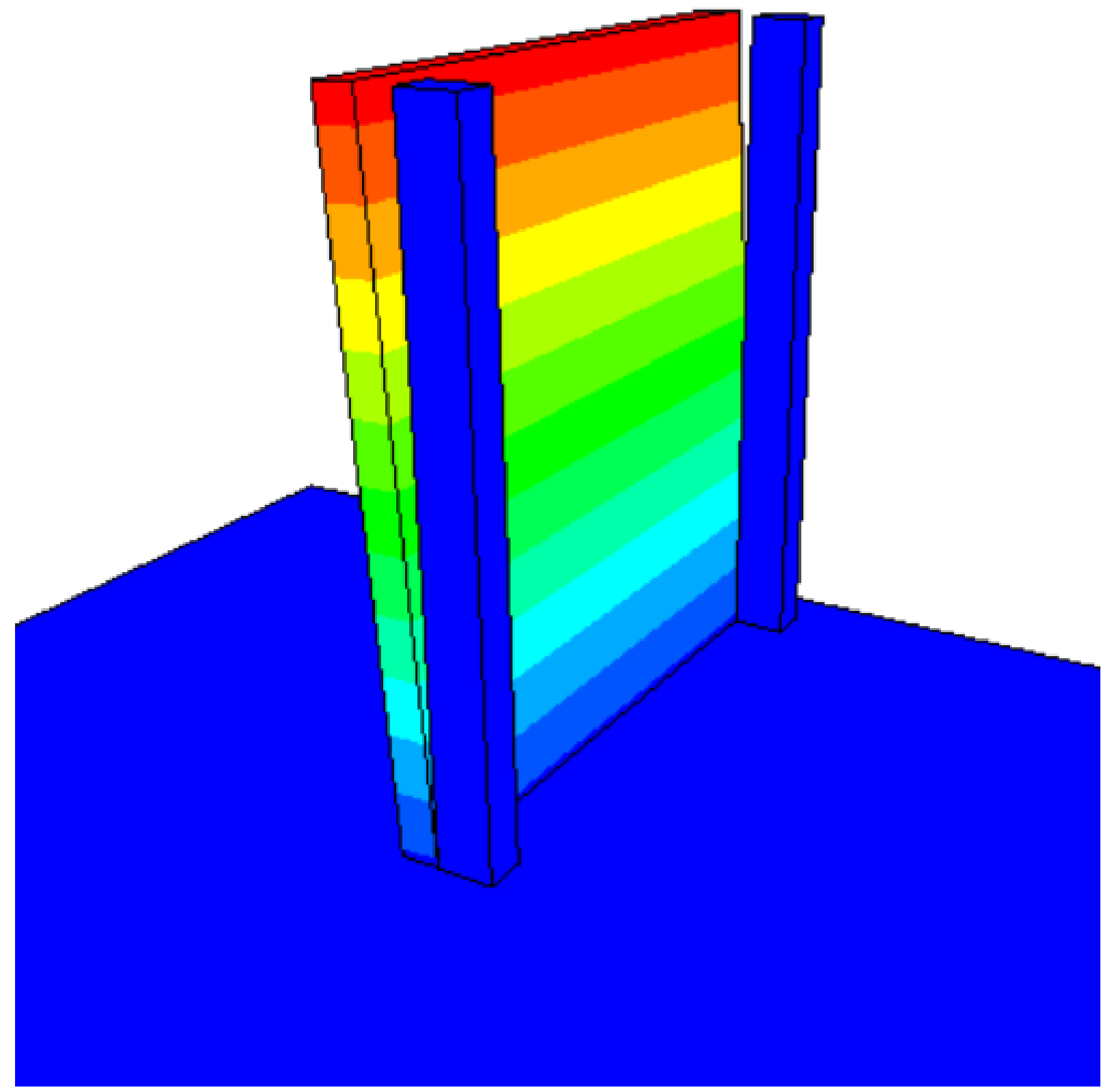

(a) W1

Figure 7: DEM modelling of rocking façade and return walls with associated block and spring interaction scheme (Colours represent displacement magnitude without scale). 


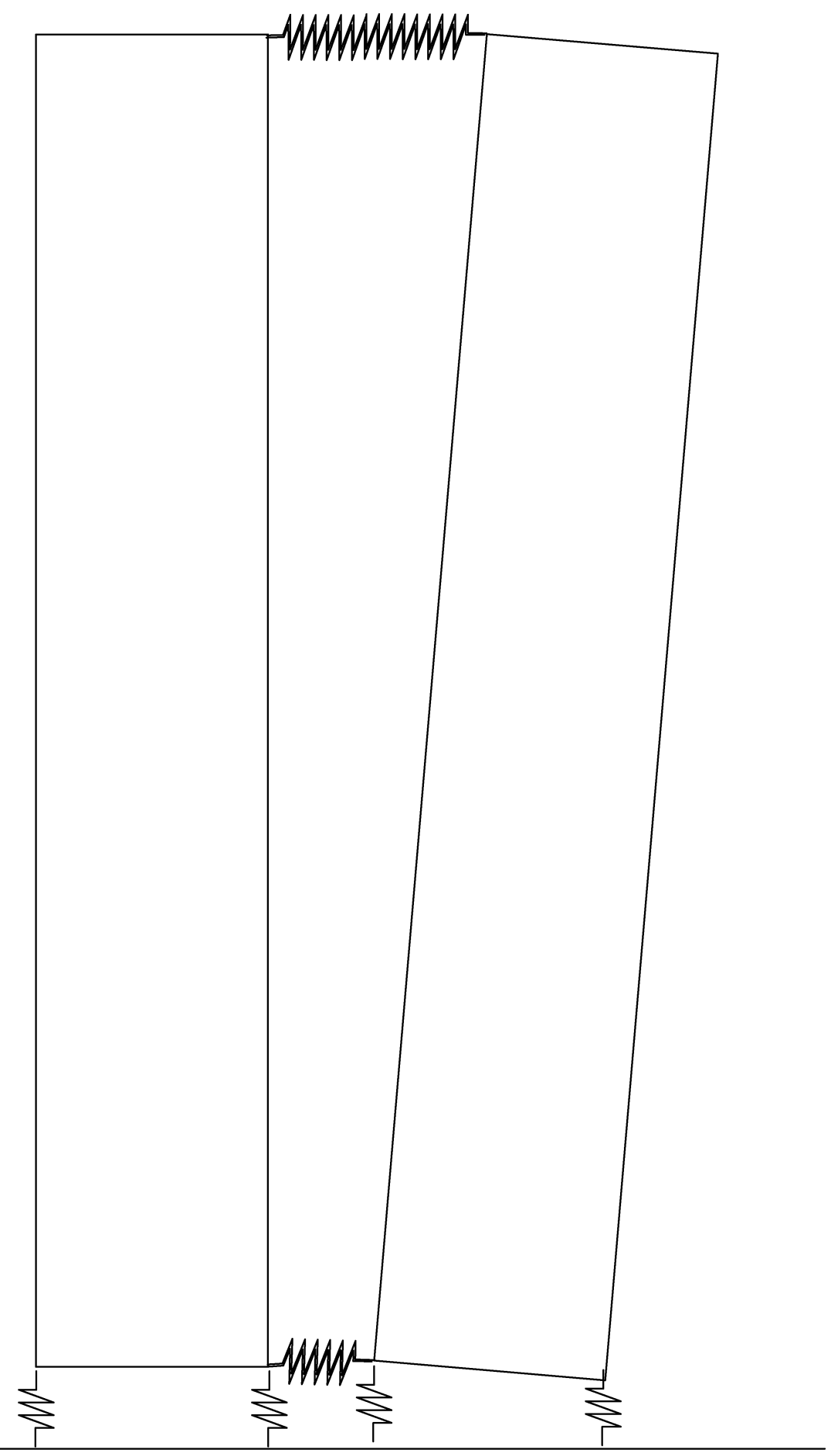

(a) W1

Figure 7: DEM modelling of rocking façade and return walls with associated block and spring interaction scheme (Colours represent displacement magnitude without scale). 


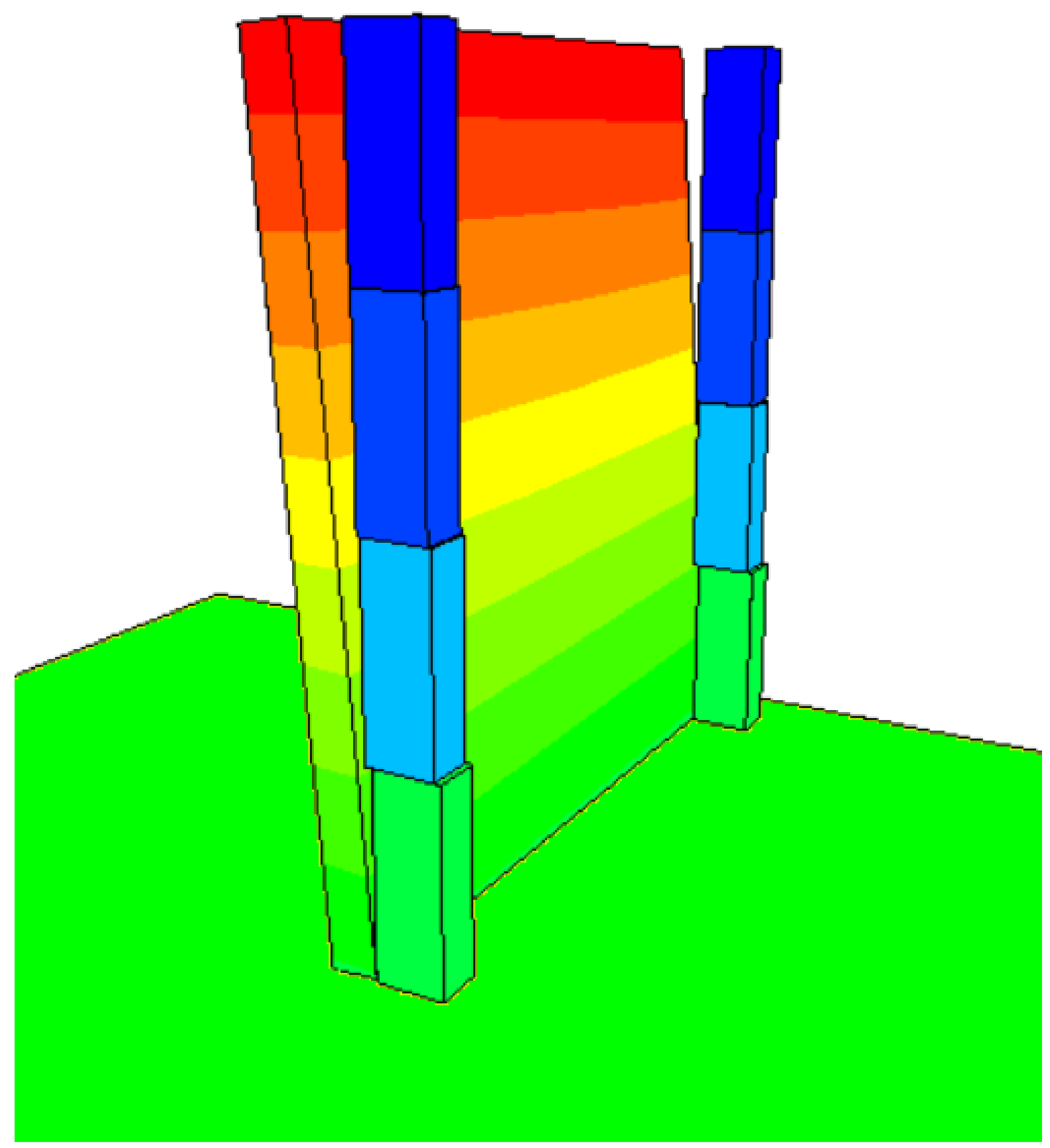

(b) $\mathrm{W} 2$

Figure 7: DEM modelling of rocking façade and return walls with associated block and spring interaction scheme (Colours represent displacement magnitude without scale). 


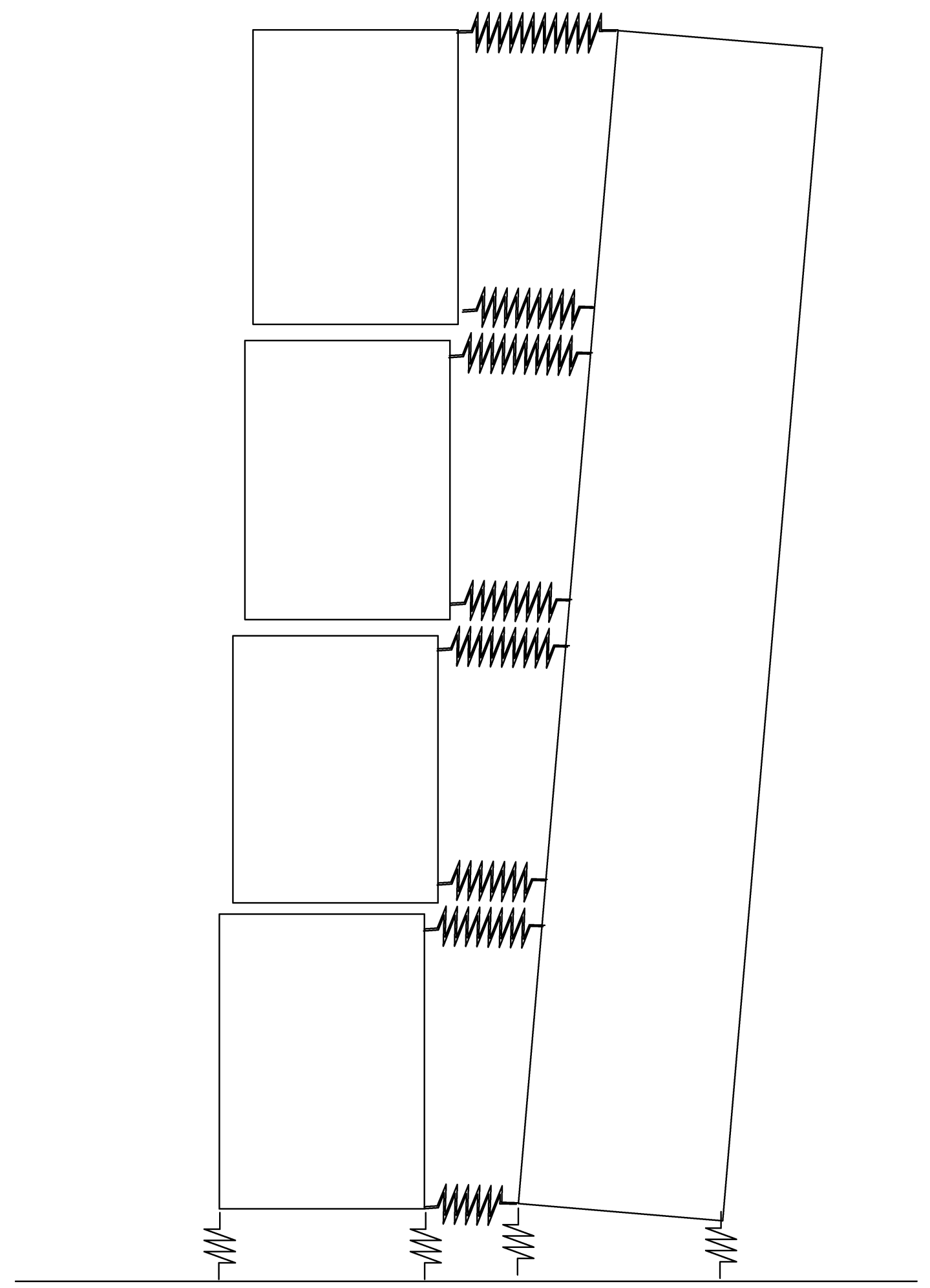

(b) W2

Figure 7: DEM modelling of rocking façade and return walls with associated block and spring interaction scheme (Colours represent displacement magnitude without scale). 


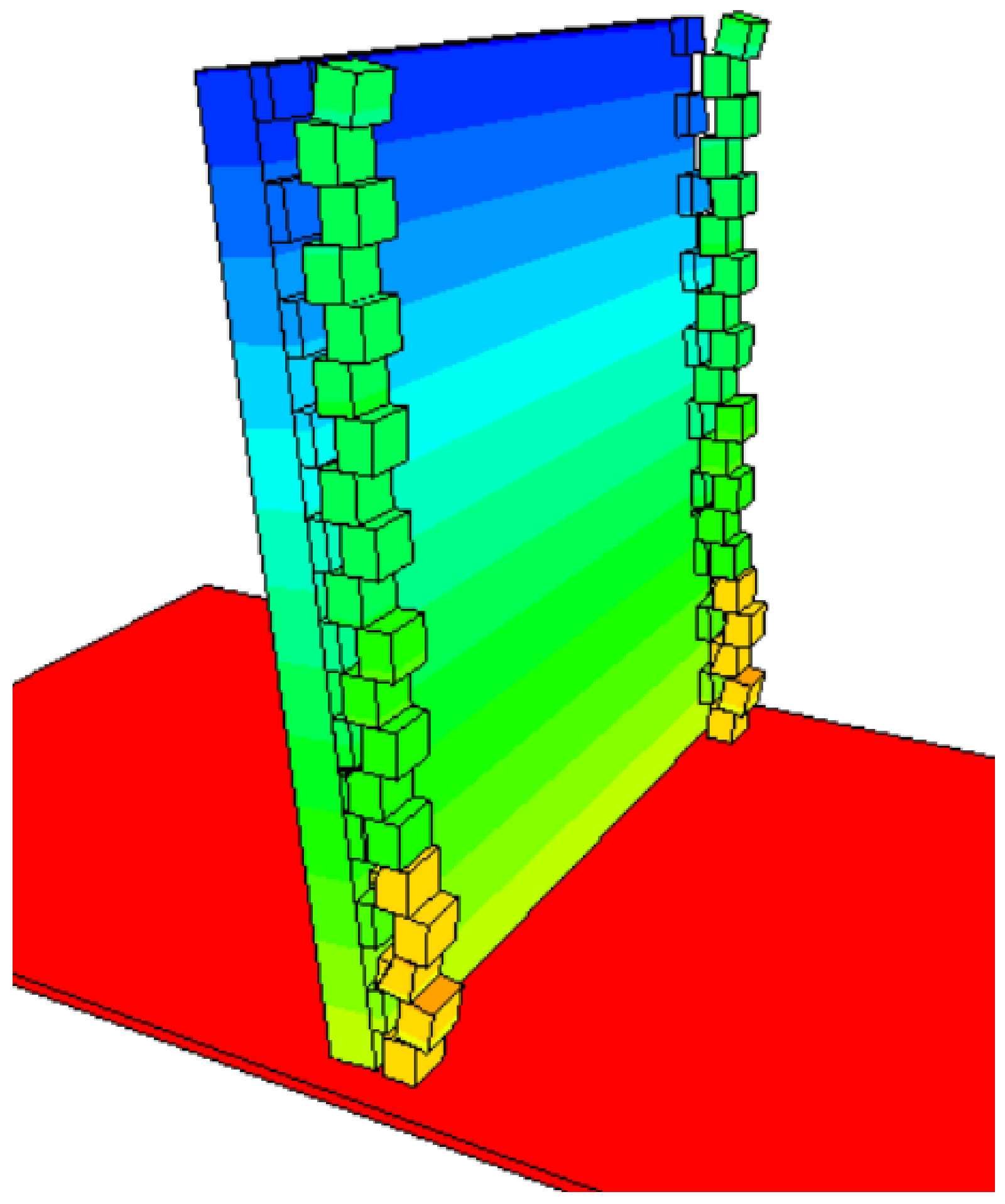

(c) W3

Figure 7: DEM modelling of rocking façade and return walls with associated block and spring interaction scheme (Colours represent displacement magnitude without scale). 


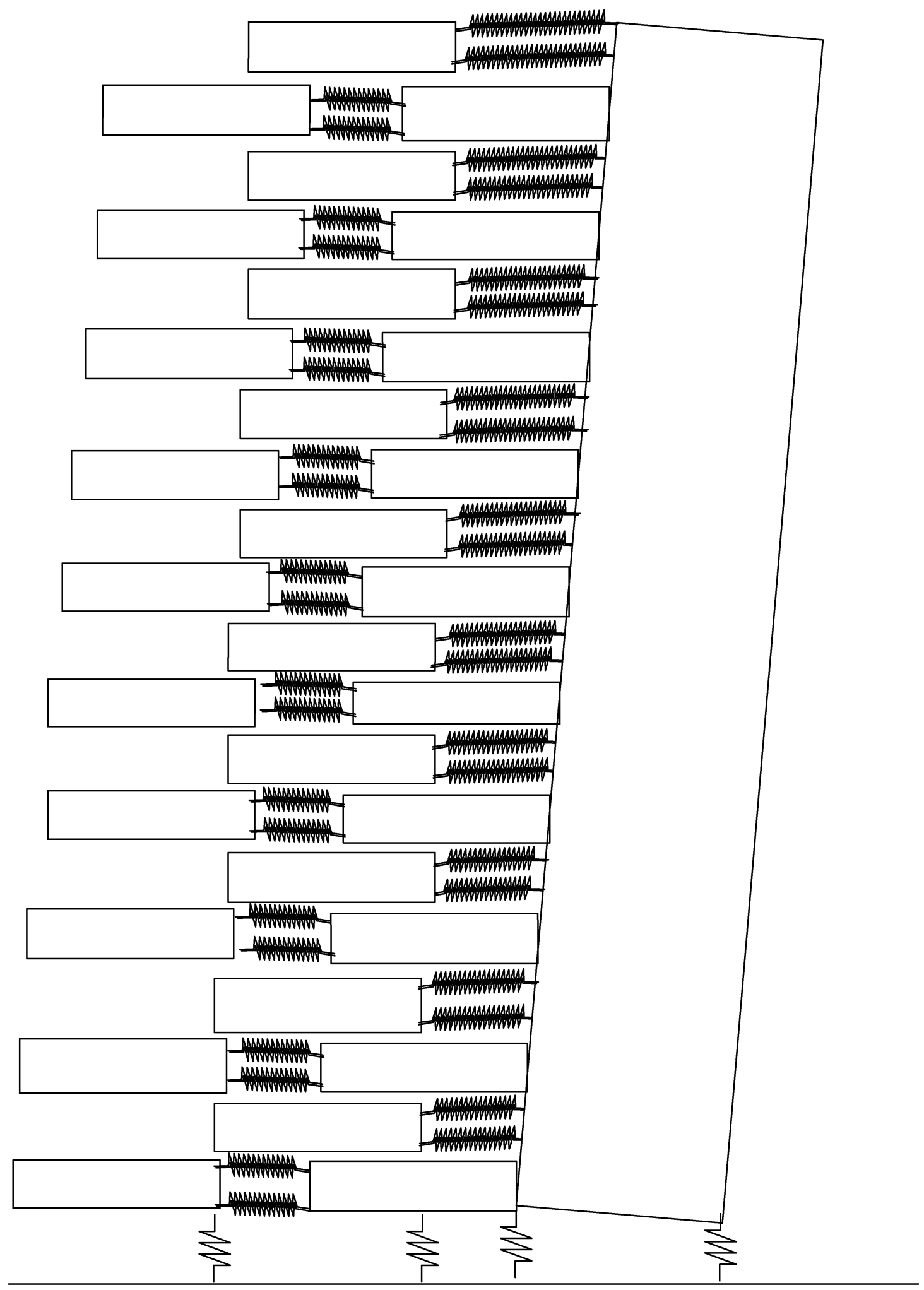

(c) W3

Figure 7: DEM modelling of rocking façade and return walls with associated block and spring interaction scheme (Colours represent displacement magnitude without scale). 


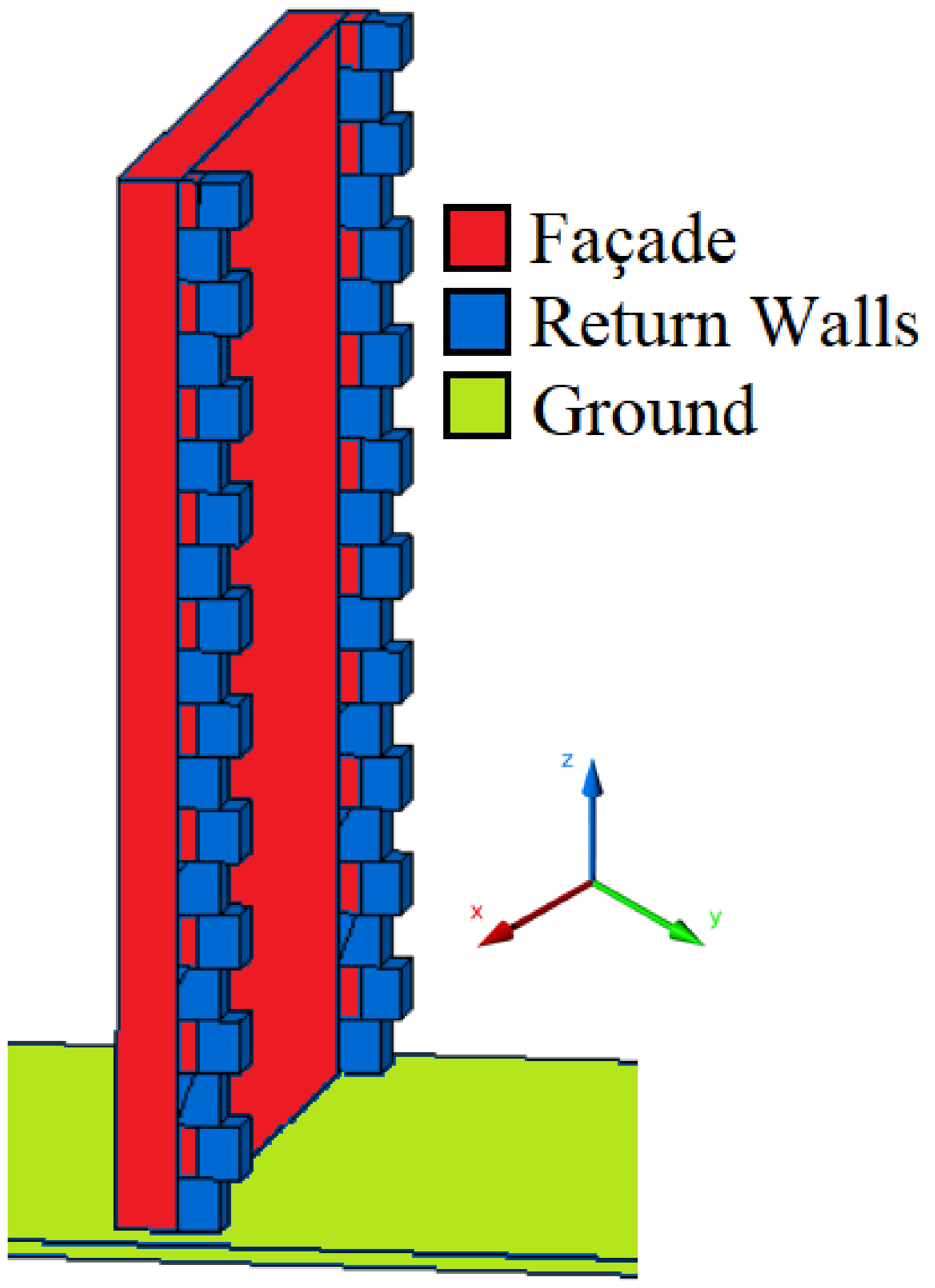

(a) Elements in W3

Figure 8: W3 details and capacity curve 


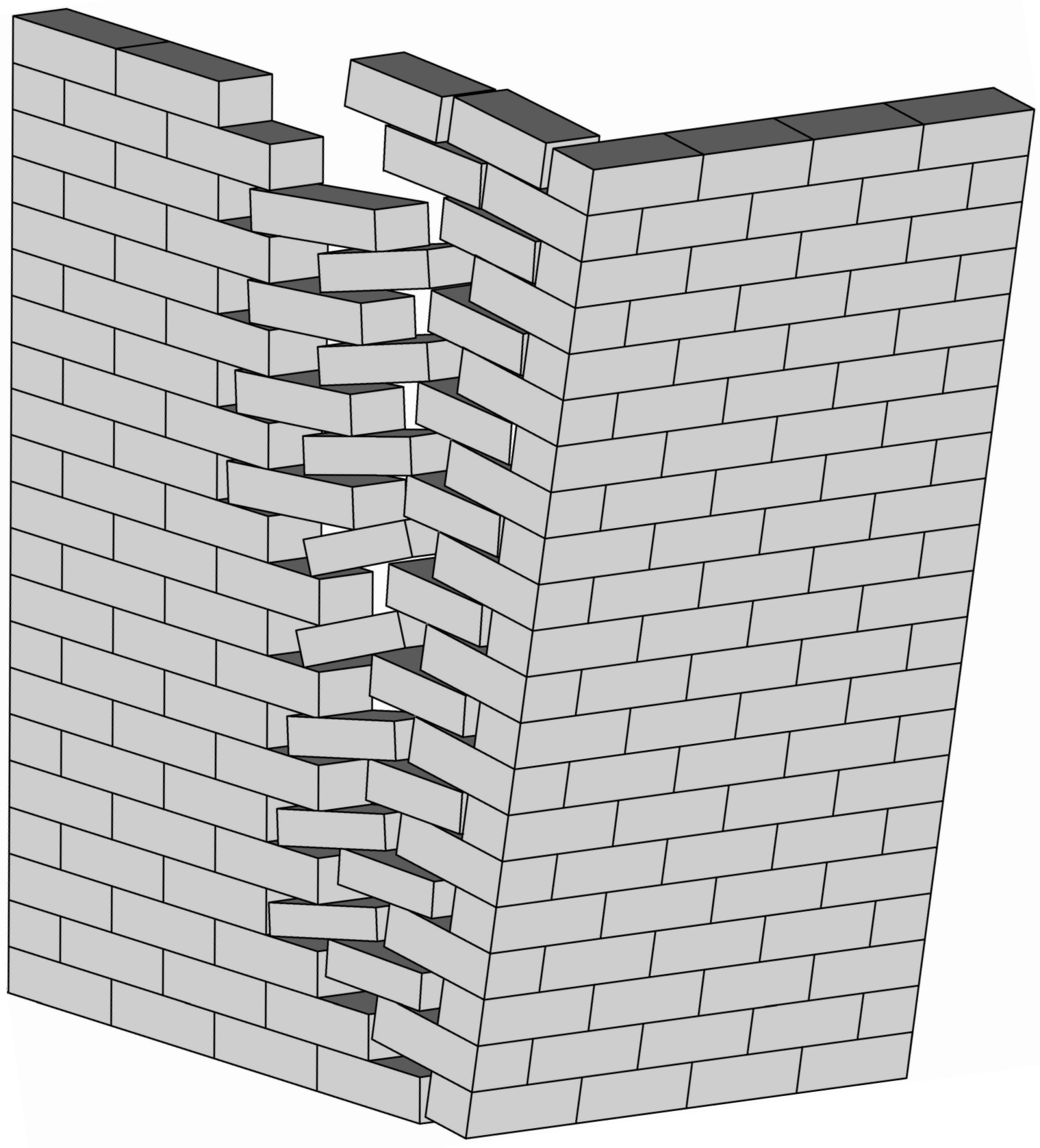

(b) Scheme of generic façade and return wall separation

Figure 8: W3 details and capacity curve 


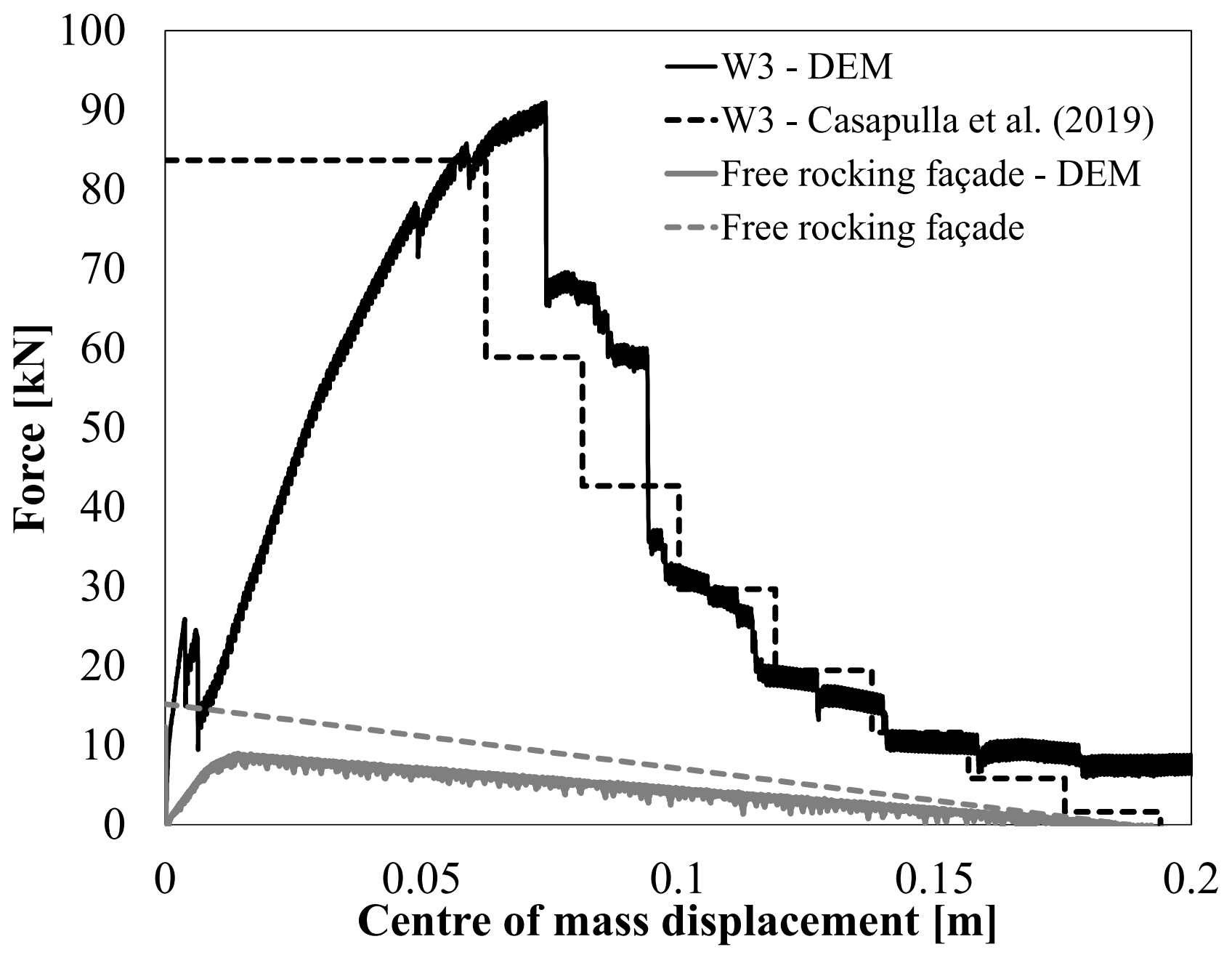

(c) Comparison between kinematic and DEM capacity curve

Figure 8: W3 details and capacity curve 


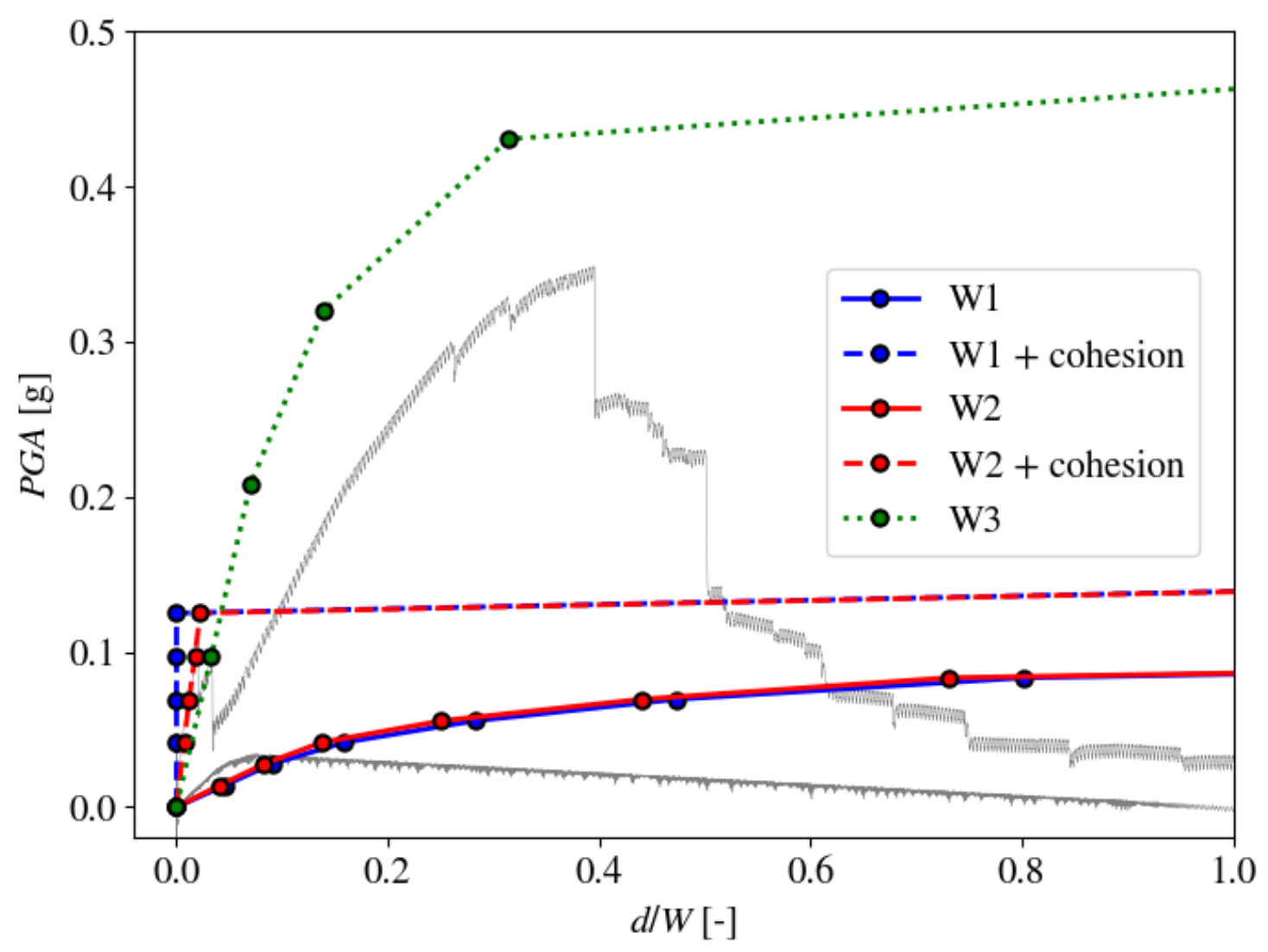

(a) BUCAR0 - Positive (+) direction

Figure 9: Incremental dynamic analyses. Pushover curves in grey for reference. 


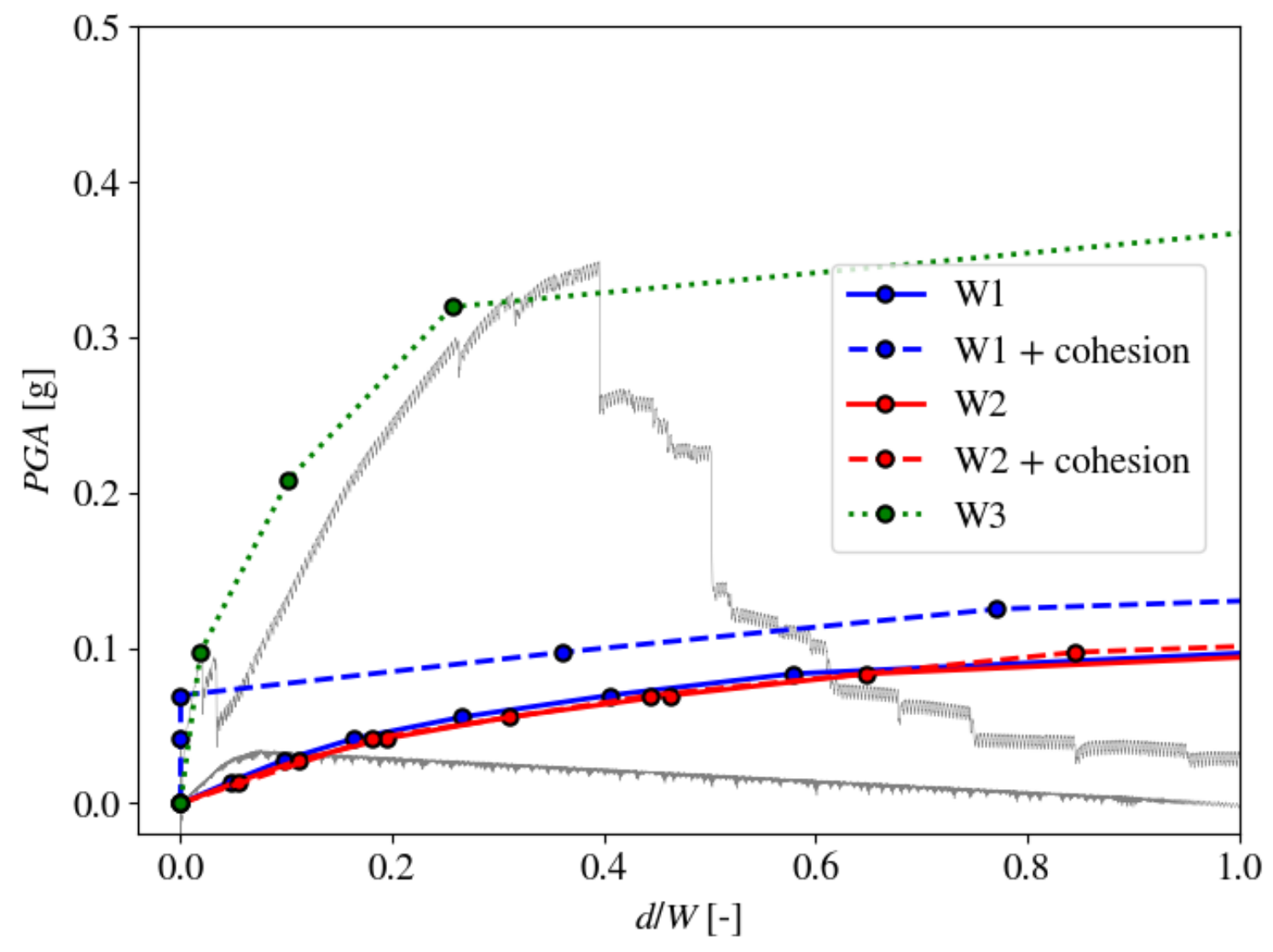

(a) BUCAR0 - Negative (-) direction

Figure 9: Incremental dynamic analyses. Pushover curves in grey for reference. 


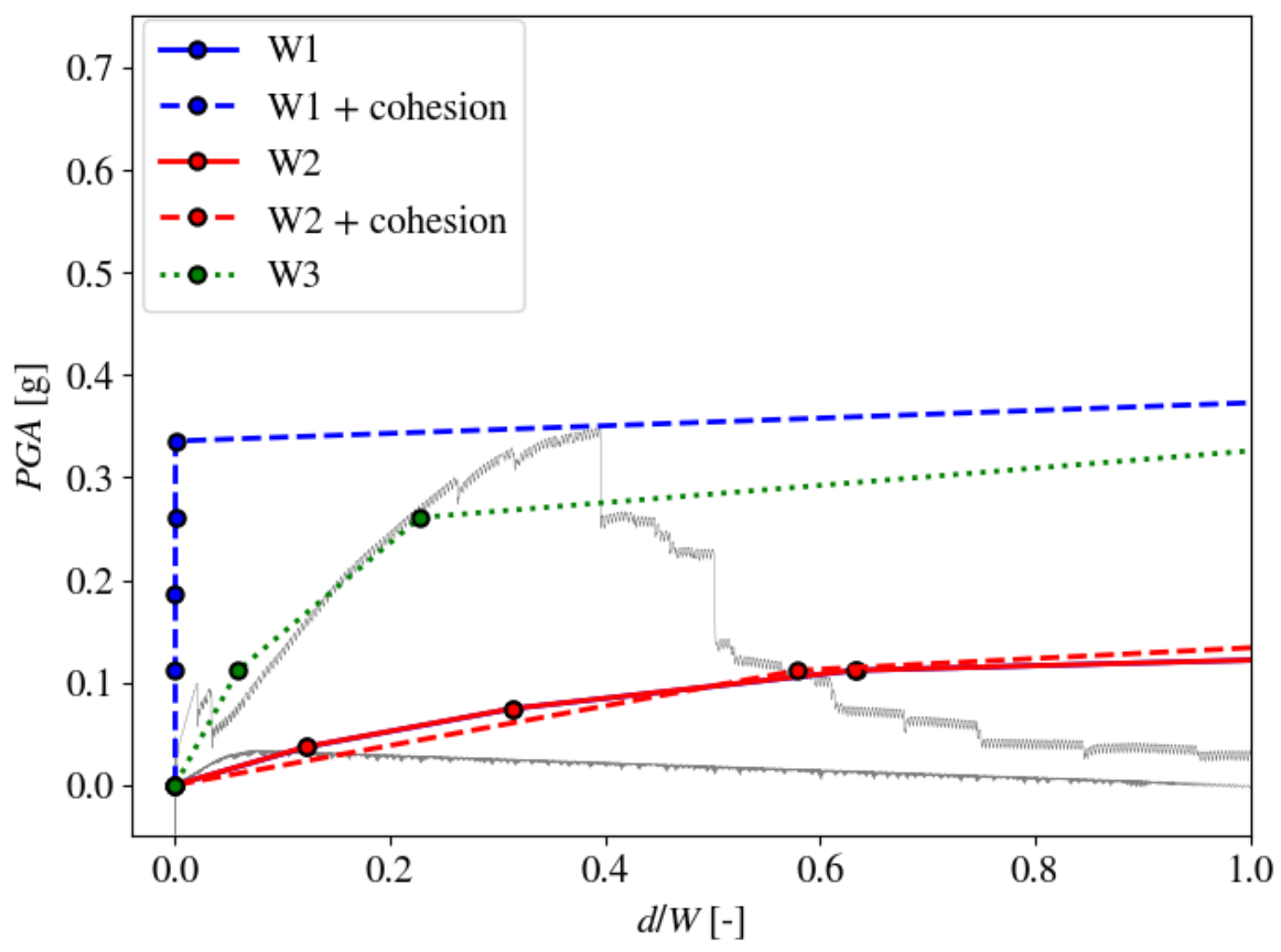

(b) RRS228 - Positive (+) direction

Figure 9: Incremental dynamic analyses. Pushover curves in grey for reference. 


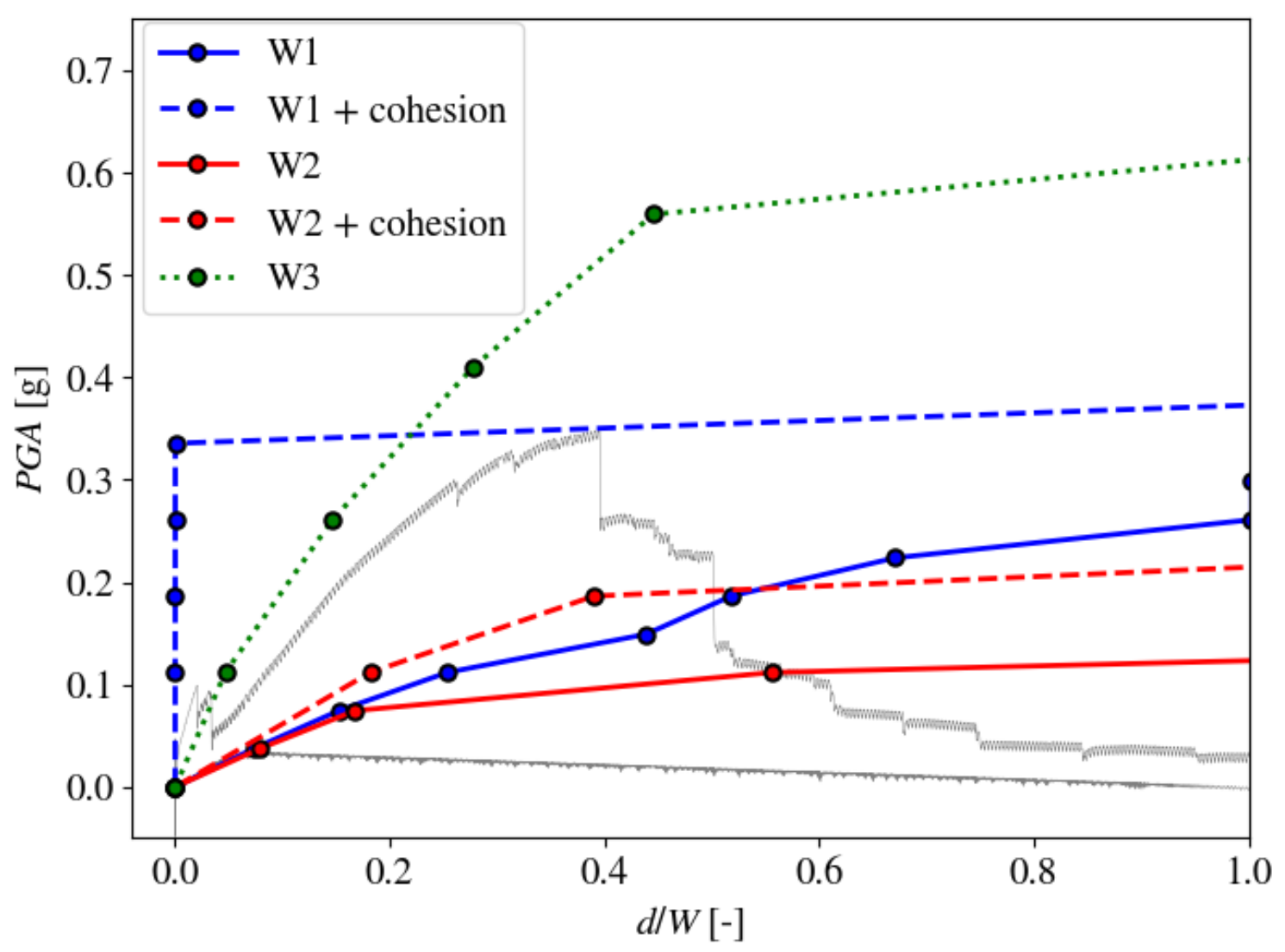

(b) RRS228 - Negative (-) direction

Figure 9: Incremental dynamic analyses. Pushover curves in grey for reference. 


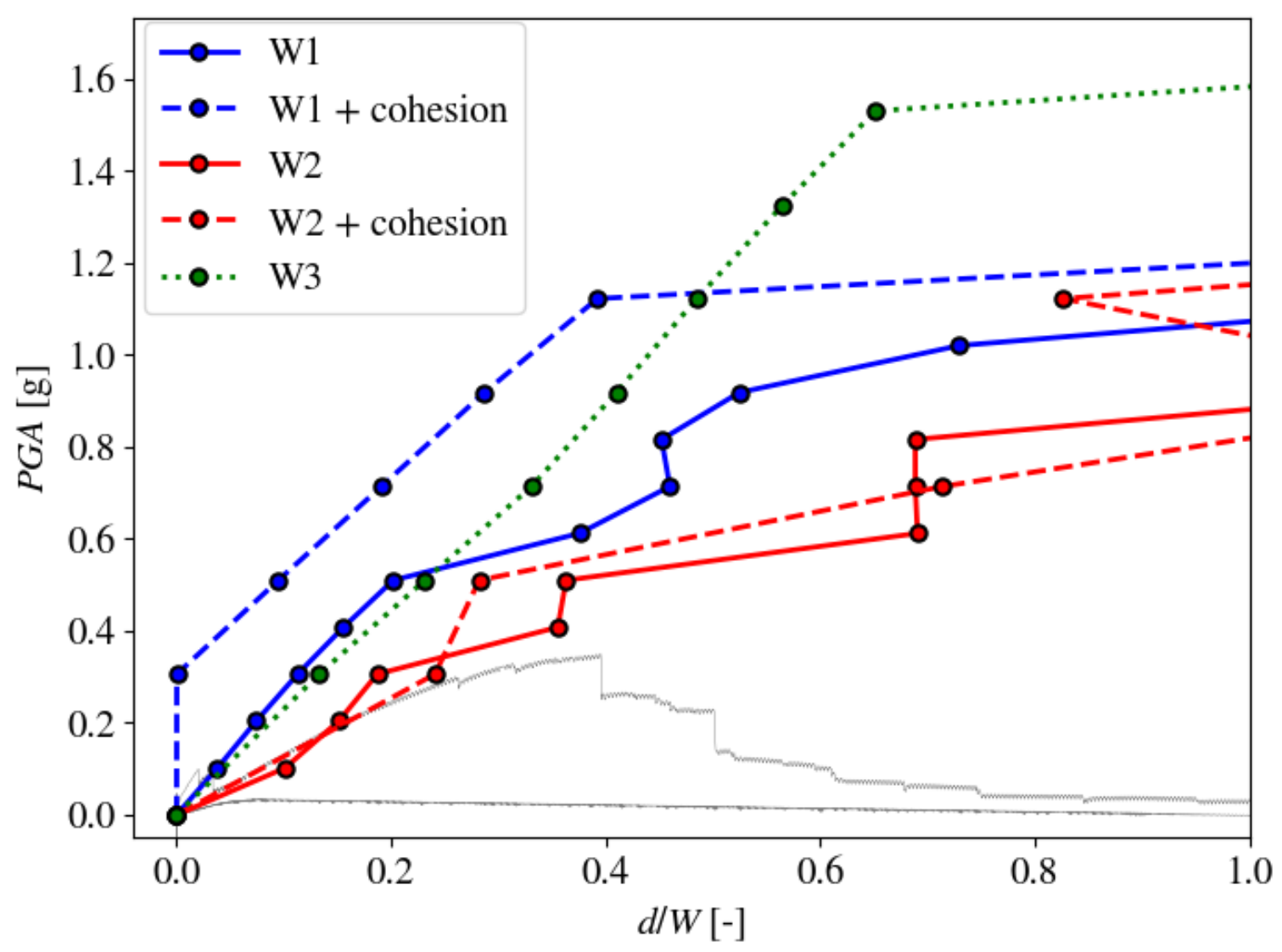

(c) 1ST280 - Positive (+) direction

Figure 9: Incremental dynamic analyses. Pushover curves in grey for reference. 


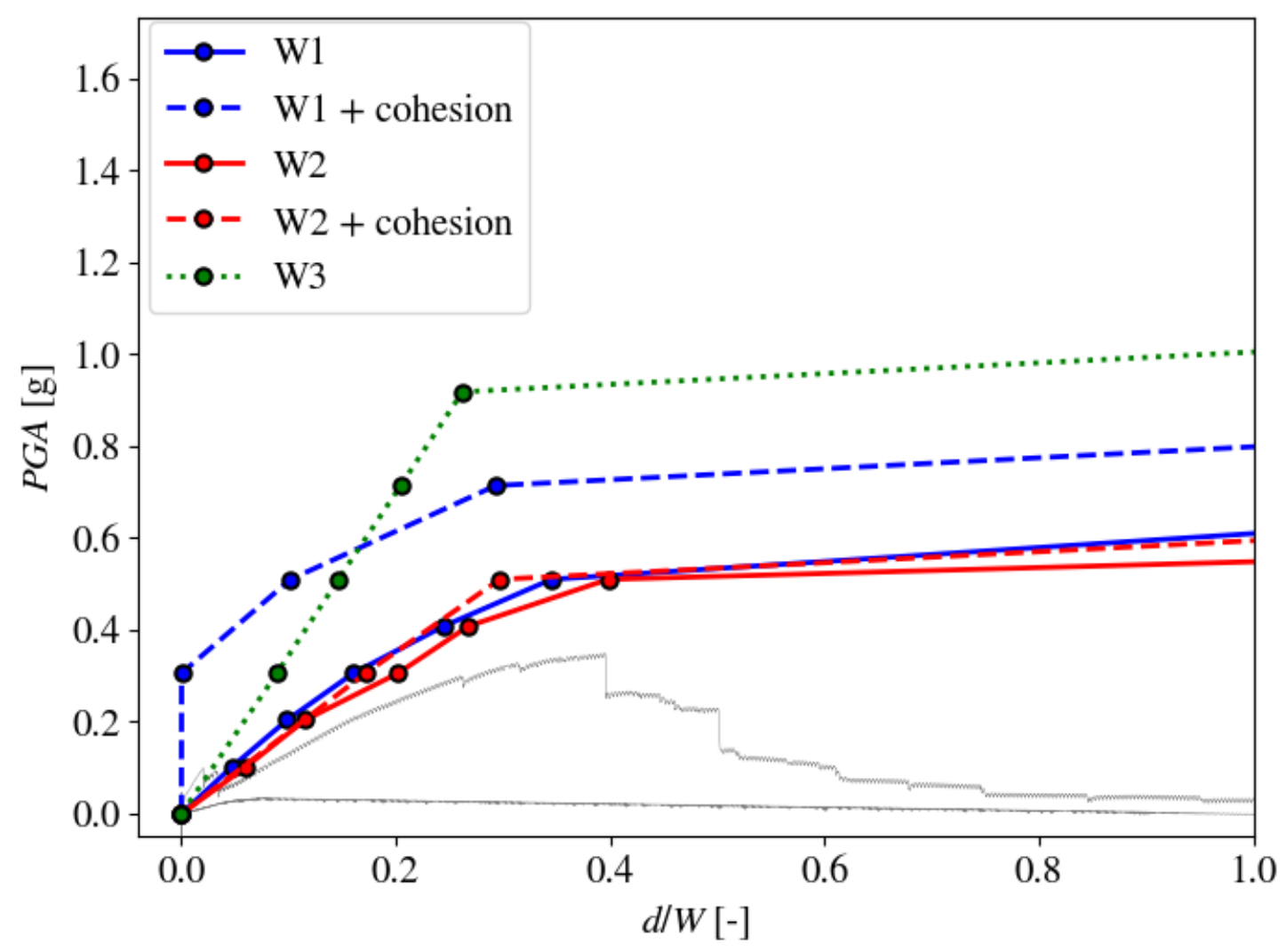

(c) 1ST280 - Negative (-) direction

Figure 9: Incremental dynamic analyses. Pushover curves in grey for reference. 


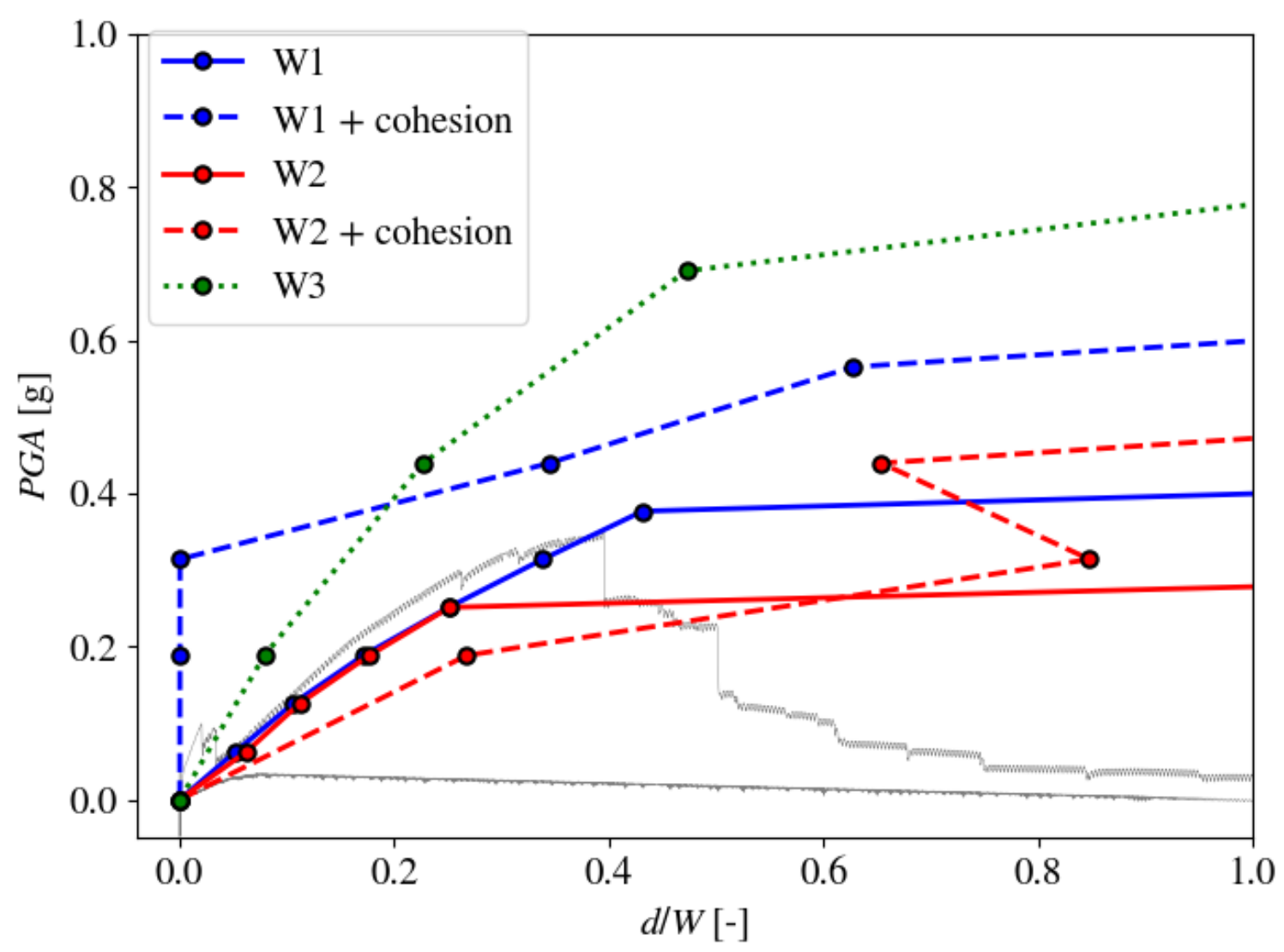

(d) HVSC1 - Positive (+) direction

Figure 9: Incremental dynamic analyses. Pushover curves in grey for reference. 


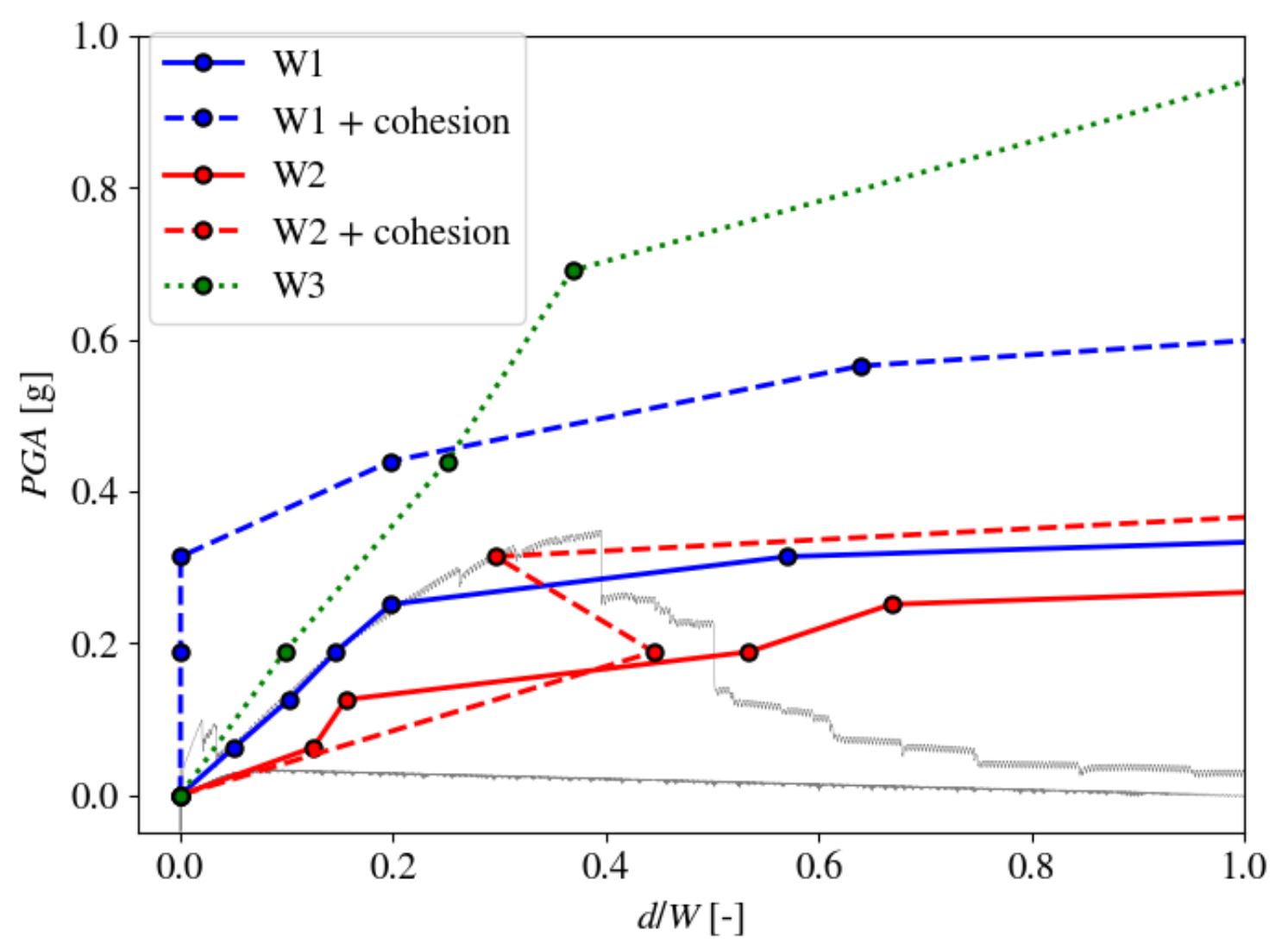

(d) HVSC1 - Negative (-) direction

Figure 9: Incremental dynamic analyses. Pushover curves in grey for reference. 